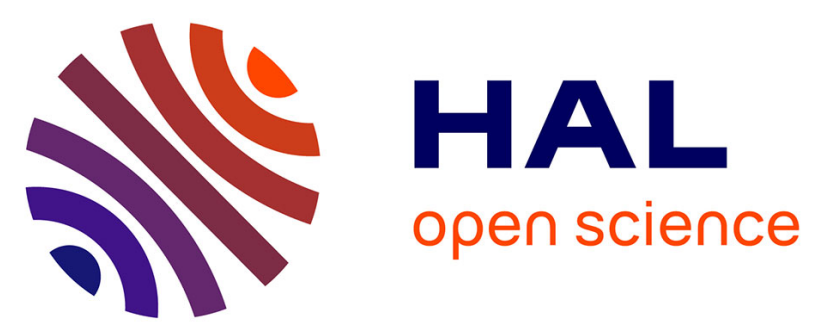

\title{
Geomorphological controls on groundwater transit times:a synthetic analysis at the hillslope scale
}

Alexandre Gauvain, Sarah Leray, Jean Marçais, Clément Roques, Camille Vautier, Frédéric Gresselin, Luc Aquilina, Jean-Raynald de Dreuzy

\section{To cite this version:}

Alexandre Gauvain, Sarah Leray, Jean Marçais, Clément Roques, Camille Vautier, et al.. Geomorphological controls on groundwater transit times:a synthetic analysis at the hillslope scale. Water Resources Research, 2021, 57 (7), pp.e2020WR029463. 10.1029/2020WR029463 . insu-03283671

\section{HAL Id: insu-03283671 https://hal-insu.archives-ouvertes.fr/insu-03283671}

Submitted on 12 Jul 2021

HAL is a multi-disciplinary open access archive for the deposit and dissemination of scientific research documents, whether they are published or not. The documents may come from teaching and research institutions in France or abroad, or from public or private research centers.
L'archive ouverte pluridisciplinaire HAL, est destinée au dépôt et à la diffusion de documents scientifiques de niveau recherche, publiés ou non, émanant des établissements d'enseignement et de recherche français ou étrangers, des laboratoires publics ou privés. 


\section{Geomorphological controls on groundwater transit times: a synthetic analysis at the hillslope scale}

Alexandre Gauvain ${ }^{1}$, Sarah Leray ${ }^{2}$, Jean Marçais ${ }^{3}$, Clément Roques ${ }^{1}$, Camille Vautier ${ }^{1}$, Frédéric Gresselin ${ }^{4}$, Luc Aquilina ${ }^{1}$, Jean-Raynald de Dreuzy ${ }^{1}$

${ }^{1}$ Univ Rennes, CNRS, Géosciences Rennes - UMR 6118, F-35000 Rennes, France.

${ }^{2}$ Departamento de Ingeniería Hidráulica y Ambiental, Pontificia Universidad Católica de Chile, Santiago, RM, Chile.

${ }^{3}$ INRAE, UR RiverLy, F-69625 Villeurbanne, France.

${ }^{4}$ DREAL Normandie, F-14006 Caen, France.

Corresponding author: Alexandre Gauvain (alexandre.gauvain@univ-rennes1.fr, alexandre.gauvain.ag@gmail.com)

\section{Key points}

Transit times are determined by integrated features of groundwater and seepage distribution in constant-slope convergent/divergent hillslopes

The coefficient of variation of the transit time distribution scales linearly with the mean distance of the groundwater volume to the river

The extent and structure of seepage modify the groundwater outlet and impact the distribution of transit time and increase its variability

This article has been accepted for publication and undergone full peer review but has not been through the copyediting, typesetting, pagination and proofreading process, which may lead to differences between this version and the Version of Record. Please cite this article as doi: 10.1029/2020WR029463.

This article is protected by copyright. All rights reserved. 


\begin{abstract}
We investigated how geomorphological structures shape Transit Time Distributions (TTDs) in shallow aquifers. Extensive 3D simulations were performed to determine the TTDs for synthetic convergent, straight and divergent hillslopes with a constant slope. The uniform recharge applied on top of the aquifer is transferred to the receiving stream through steady-state groundwater flows, return flows and saturation excess overland flows. Without seepage, TTDs evolve from uniform- to power law-like- distributions depending on the average distance of the groundwater volume to the river (barycenter). Remarkably, the coefficient of variation (ratio of the standard deviation to the mean) of the TTDs scales linearly with the barycenter in agreement with a theoretical prediction based on three analytical approximations derived for specific cases. With seepage, the TTD has three separate modes corresponding to rapid saturation excess overland flows, to the intermediate flow paths ending in seepage area and to the slower flow paths going all the way to a discharge in the river. The coefficient of variation additionally depends on the extent of the seepage area. For a natural hillslope in the crystalline basement of Normandy (France), the same synthetic analysis demonstrates that the coefficient of variation is not only determined by the extent of the seepage zone but also by its structure in relation to the local and global geomorphological organization. The results suggest the possibility to assess the variability of transit times by combining geomorphological analysis, surface soil saturation observations and environmental tracers.
\end{abstract}

This article is protected by copyright. All rights reserved. 


\section{Introduction}

Water transit times vary over several orders of magnitude in between and within each of the main compartments of the hydrological cycle (Sprenger et al., 2019). This distribution has fundamental consequences for the water availability, renewal (Gleeson et al., 2016; Jasechko et al., 2017) and quality (Appelo \& Postma, 1994; Wachniew et al., 2016). This is especially the case for shallow aquifers in direct connection to anthropogenic activities. Water ages broadly range from some weeks to several decades. This has immediate consequences on the transmission or buffering of recharge deficits and contamination loads (Cuthbert et al., 2019). Being intermediary between the surface and the deeper subsurface, shallow subsurface flows are potentially controlled by both geology and geomorphology (Bresciani et al., 2016; Fan \& Bras, 1998; Haitjema \& Mitchell- Bruker, 2005). Globally, they follow the conductive subsurface structures down topographical gradients and discharge in saturated zones (Fetter, 2000; Leray et al., 2012; Ogden \& Watts, 2000). Yet, it remains largely unknown how geology and geomorphology shape the Transit Time Distribution (TTD). Transit time is defined here as the time needed for any parcel of water to go from its recharge in the groundwater system to its discharge in the receiving water bodies (e.g. stream, lake). In this study, we distinguish "geology" from "geomorphological" constraints based on the effective hydraulic parameters and the structure of the topography respectively.

The controls of geology on flow partitioning and transit times has mainly been addressed for global aquifer structures. For subsurface flows, the mean transit time directly scales with the overall volume of the aquifer (Bolin \& Rodhe, 1973; Cornaton \& Perrochet, 2006; Eriksson, 1971) regardless the degree of its internal heterogeneity (Bethke \& Johnson, 2002). In semiconfined aquifers where geology is the dominant controlling factor through the aquifer thickness, the shape of the TTD under uniform recharge follows the distribution of water within the system (Leray et al., 2019). The TTD is exponential when the aquifer volume is uniformly distributed (Haitjema, 1995) or without any marked trends (Luther \& Haitjema, 1998). It evolves to power-law like distributions with higher standard deviations when the aquifer volume is located further away from the outlet (Etcheverry \& Perrochet, 2000). It becomes uniform with lower standard deviations when the aquifer volume is clustered close to the outlet (Etcheverry, 2001; IAEA, 2006; Leray et al., 2019; Małoszewski \& Zuber, 1982). The variability of the distribution increases with the relative distance of the saturated volume to the outlet. Even though the structure of the aquifer appears to be a primary driver of the shape of

This article is protected by copyright. All rights reserved. 
the TTD (Eberts et al., 2012; Leray et al., 2012, 2016), it has been mainly related to the hillslope geological characteristics and much less to its geomorphological characteristics.

However, geomorphology is a primary controlling factor of the dynamics of surface and shallow subsurface flows (Beven \& Wood, 1983; Rodríguez-Iturbe \& Valdés, 1979). Response functions to climatology have been and remain an active field of research at the integrated regional scales (Condon \& Maxwell, 2015), at the catchment scale (Ambroise et al., 1996; Cudennec et al., 2004; Hrachowitz et al., 2013) and at the more local hillslope scale involving mechanistic models of Boussinesq flows (Berne et al., 2005; Bogaart \& Troch, 2006; Lyon \& Troch, 2007). Climatic conditions and topographic structures (e.g. slope, flow path distances over flow gradients) directly impact the saturation state and condition transit times as shown by global analyses across different geomorphic provinces (McGuire et al., 2005; Tetzlaff et al., 2009).

Fewer studies have investigated the direct control of topography on transit times partly because of the inherent difficulty to untangle the effects of climate and topography (Remondi et al., 2019; Seeger \& Weiler, 2014). Analyses based on mechanistic models calibrated for wellinstrumented sites have confirmed the dependence of the mean transit time on the catchment wetness with seasonal shifts in the contribution of shallower and deeper flow paths (Remondi et al., 2018; Yang et al., 2018). The fraction of young water increases with the mean slope (Remondi et al., 2019) suggesting an effect of topographic structures on the TTD This link between the distribution of groundwater, the geomorphological structures, the TDD and associated control factors is however not clearly established.

Here, we investigate how geology and geomorphology shape Transit Time Distributions for shallow free aquifers conditions at the hillslope scale. We define "local" as the conditions for which flow lines dominantly end up in the closest river downhill and only marginally go below the stream to eventually reach another outlet (Gburek \& Folmar, 1999). Thus, the local scale is typically the hydrologically defined hillslope (Kirkby, 1978). Using 3D steady-state flow and transport simulations, as well as simplified analytical developments for a synthetic hillslope model, we analyze the influence of the aquifer and topographic structures on the mean and standard deviation of the TDD. The coefficient of variation (or relative standard deviation) defined as the ratio of the standard deviation to the mean of the TTD, is used to determine the relative dispersion and the shape of the TTD. We seek to relate it to geomorphological and hydrological indices that may be inferred in natural hillslopes. We more specifically explore indices related to the distribution of the effective water volume within the aquifer and its

This article is protected by copyright. All rights reserved. 
interaction with the surface through the characterization of the seepage area. We assess the relevance of these indices on models of natural hillslopes in a crystalline basement area of Normandy (France). We discuss their application in conjunction with age tracers to assess hillslope Transit Time Distributions.

\section{Hillslope structures, flow and transport models and methods}

\subsection{Synthetic Hillslopes}

Synthetic hillslopes (Figure 1) that were modeled were classic convergent, straight and divergent hillslopes used in several previous studies (Fan \& Bras, 1998; Marçais et al., 2017; Matonse \& Kroll, 2009; Troch et al., 2003).

Hillslopes extend over a length $L[\mathrm{~L}]$ from the river downstream $(x=0)$ to the water divide upstream $(x=L)$. Hillslopes have a constant thickness $H_{0}$ [L]and a constant slope $\Theta[-]$. Both the surface and the soil-bedrock interface have the same tilt $\Theta$. Hillslope shape is defined by the shape coefficient $C_{W}[-]$ :

$$
C_{W}=W_{0} / W_{L}
$$

where $W_{0}[\mathrm{~L}]$ is the downstream hillslope width and $W_{L}[\mathrm{~L}]$ the upstream hillslope width. The hillslope width $W(x)[\mathrm{L}]$ is a linear function of the distance to the river $x$ :

$$
W(x)=\frac{W_{L}-W_{0}}{L} x+W_{0}=W_{L}\left[1+\left(C_{W}-1\right)\left(1-\frac{x}{L}\right)\right] .
$$

Hillslopes are convergent when $C_{W}<1$, straight for $C_{W}=1$ and divergent for $C_{W}>1$. The hydraulic conductivity $K\left[\mathrm{~L} . \mathrm{T}^{-1}\right]$ is constant throughout the system and the recharge rate $R\left[{\mathrm{~L} . \mathrm{T}^{-}}^{-}\right.$ ${ }^{1}$ ] is uniformly distributed.

The shape coefficient $C_{W}$, the tilt $\Theta$, the thickness to length ratio $H_{0} / L$ and the recharge to hydraulic conductivity ratio $R / K$ condition the thickness of the aquifer and its intersection with the surface. These parameters were varied over a broad range of values (see section 3.5) to provide a large variety of hillslope configurations: from thin hillslopes $\left(H_{0} / L=10^{-2}\right)$ to thick hillslopes $\left(H_{0} / L=10^{-1}\right)$, from highly convergent hillslopes $\left(C_{W}=10^{-2}\right)$ to highly divergent hillslopes $\left(C_{W}=10^{2}\right)$, and from flat hillslopes $(\Theta=0 \%)$ to steep hillslopes $(\Theta=10 \%)$. To study the impact of the seepage area, we simply added a topographic limit allowing the development of the seepage area $A_{S}\left[\mathrm{~L}^{2}\right]$. This limit is placed in such a way that the thickness is fixed to $H_{0}$ (distance between the surface and the bedrock limit).

This article is protected by copyright. All rights reserved. 


\subsection{Natural Hillslope}

We additionally analyzed a natural hillslope structure in the western part of Normandy (France). The hillslope is defined on the basis of the hydrological catchment and extracted by defining all surface flow paths to a limited section of a downstream perennial river close to the Atlantic coast. The extraction was performed using TopoToolbox (Schwanghart \& Scherler, 2014). The hillslope is approximately $3 \mathrm{~km}$ by $1 \mathrm{~km}$. The elevation range varies between $5 \mathrm{~m}$ and $70 \mathrm{~m}$. It is almost straight $\left(C_{W}=2.43\right)$ with a cliff at the limit between relatively flat upstream and downstream sections (Figure 2). Such cliffs are common in this area. They are mainly due to a transition between an overlying crystalline basement with permeable upper layer dipping below a sedimentary prism composed of sands, both resting on the same impermeable bedrock (Doré et al., 1988; Dupret et al., 1987). In spite of some degree of heterogeneity, the hydraulic conductivity and porosity are assumed to be homogeneous so as to focus on the sole effect of the morphology of the aquifer. The aquifer is mostly shallow with typical depths much smaller than its lateral extents, similar to the synthetic hillslopes. The recharge is assumed uniform, considering the moderate relief of the area. Natural and synthetic cases differ by the roughness of the topography and of the soil-bedrock interface. In the synthetic case, the topography is gently increasing with a constant slope from the river to the hillslope divide. In the natural case, the slope varies along the major cliff structure and has smaller scale local depressions. To investigate the relative effects of the local and global scale structures, we use the DTM at a resolution of $5 \mathrm{~m}$ (IGN, 2018) and smoothed topographies obtained by using the moving average function "filter" of TopoToolbox (Schwanghart \& Scherler, 2014) parameterized by a smoothing scale (Figure 2c-d). The studied topographies thus range from the one with "natural" roughness to the synthetic one where only the larger wavelengths are maintained.

\subsection{Flow model}

Hydrodynamic flow and transport models were applied both to the synthetic and natural hillslopes. Flows were modeled by the Laplace equation (Bear, 1972; Bresciani et al., 2014; Neuman \& Witherspoon, 1970):

$$
\nabla .(K \nabla h)=0 \text { in } \Omega
$$

where $h[\mathrm{~L}]$ is the hydraulic head and $K\left[{\left.\mathrm{~L} . \mathrm{T}^{-1}\right]}^{-1}\right.$ is the hydraulic conductivity. $K$ is assumed to be homogeneous and isotropic. The Laplace equation is defined for the saturated domain $\Omega$ limited upstream by the groundwater divide $\left(\Gamma_{N}\right)$, which is a no flow boundary condition:

This article is protected by copyright. All rights reserved. 


$$
K \frac{\partial h}{\partial N}=0 \text { at } \Gamma_{N}
$$

where the derivative operator is taken with respect to the exterior normal N. Downstream, at the river $\left(\Gamma_{R}\right)$, the head is fixed at a constant value $H_{0}$ :

$$
h=H_{0} \text { at } \Gamma_{R} .
$$

At the top, the free surface $\left(\Gamma_{F}\right)$ and the seepage area $\left(\Gamma_{S}\right)$ of the aquifer are represented by:

$$
\begin{aligned}
& h=z \text { at } \Gamma_{S} \text { and } \Gamma_{F}, \\
& K \frac{\partial h}{\partial N}=R \text { at } \Gamma_{F} .
\end{aligned}
$$

The recharge $R$ is uniform over the hillslope. All water infiltrates in the section where the aquifer remains below the surface. The recharge that does not infiltrate becomes a saturation excess overland flow that is directed to the downslope river. The distribution of saturation in the hillslope depends on both the hillslope structure and the recharge to hydraulic conductivity ratio $R / K$. Larger $R / K$ ratios, flatter, more convergent and thinner hillslopes promote the development of large saturated zones, which area $A_{S}$ will be compared to the hillslope area $A$ as the ratio of saturated area $A_{S} / A$. Below the surface, the aquifer structure is characterized by its volume $V\left[\mathrm{~L}^{3}\right]$ given by the integration of the cross-sectional volume $V(x)\left[\mathrm{L}^{2}\right]$ and its distribution within the hillslope relative to the river measured by the barycenter $\xi$ expressed in a dimensionless form as:

$$
\frac{\xi}{L}=\frac{\int_{0}^{L} \frac{x}{L} V(x) d x}{\int_{0}^{L} V(x) d x}
$$

\subsection{Transit times}

The volume $V$ has been previously related to the mean transit time. The organization of the volume within the hillslope characterized by $\xi / L$ will be tested as a proxy of the variability of the transit times in the aquifer. The mean transit time $\langle t\rangle$ over the porosity is directly given by the renewal rate expressed by the aquifer volume $V$ over the hillslope area $A$ multiplied by the recharge $R$ :

$$
\frac{\langle t\rangle}{\Phi}=\frac{V}{A R}
$$

This article is protected by copyright. All rights reserved. 
This equation holds regardless of the distribution of the aquifer volume within the hillslope and of the distribution of flows between the surface and the subsurface flows. Knowing the mean transit time, the coefficient of variation $C V$ is considered as a normalized expression of the transit time variability. It is expressed by:

$$
C V=\sqrt{\frac{\left\langle t^{2}\right\rangle}{\langle t\rangle^{2}}-1}
$$

To determine the transit times and their distribution, we solved the advection equation expressed in the Lagrangian framework with a classical particle tracking (Kinzelbach, 1988):

$$
\left\{\begin{array}{c}
\Phi \frac{d X\left(t_{0}, t\right)}{d t}=K \nabla h(x, y, z) \\
X\left(t=t_{0}\right)=\left(\begin{array}{c}
x_{0} \\
y_{0} \\
z_{0}=h\left(x_{0}, y_{0}\right)
\end{array}\right)
\end{array}\right.
$$

where $t[\mathrm{~T}]$ is the transit time, $t_{0}[\mathrm{~T}]$ is the initial time, $X[\mathrm{~L}]$ is the trajectory vector and $x_{0}, y_{0}$ and $z_{0}[\mathrm{~L}]$ are the initial position of the particle. The injection is carried out on the water table $z_{0}=h\left(x_{0}, y_{0}\right)$. The porosity $\Phi[-]$ is assumed uniform over the hillslope. As transit time $t$ directly scales with $\Phi$, it will be handled through its ratio to the porosity $t / \Phi$. The transport equation is made up of a sole advection term without diffusive nor dispersive terms as transit times characterize parcels of water rather than tracers.

Transit time variability is also expected to come from the relative rate of the saturation excess overland flow to the groundwater and return flows. This relative rate is typically characterized by the ratio of saturated area $A_{S} / A$. We will thus rely on $\xi / L$ and $A_{S} / A$ to describe, in a first approach, the aquifer and topographic controls of the Transit Time Distribution.

\subsection{Numerical methods}

Apart from the specific cases where analytical developments are proposed (see in section 3), the flow and transport models are solved numerically. All numerical methods are fully 3D and do not introduce any other approximations, other than errors of the numerical schemes. The MODFLOW and MODPATH software suite was used to solve the flow and transport equations (Harbaugh, 2005; Niswonger et al., 2011; Pollock, 2016). For the flow solution, hillslopes are discretized in $1 \mathrm{~m}$ by $1 \mathrm{~m}$ regular mesh cells, resulting in 275 by 1,000 mesh cells for each of the 10 layers of the model. A drainage boundary conditions is implemented at the surface. It is active when and where the saturated zone reaches the surface. The TTDs are obtained from 
particles injected on the aquifer surface, regularly spaced, weighted proportionally to the recharge magnitude, and transported forward in time to the river. The transit time of the particles injected over the outflow zone of the seepage area is considered much shorter than that of any other particles transported underground and is considered null, the particle reaching instantaneously the stream. The transit time of the particles injected over the recharge area are obtained from equation (11) Error! Reference source not found.. The FloPy Python package is used to generate and handle simulations (Bakker et al., 2016).

This article is protected by copyright. All rights reserved. 


\section{Analytical derivation of TTDs for specific hillslope structures}

Four analytical developments are proposed to explore the relation between the coefficient of variation of the transit times and the barycenter (i.e., center of mass) of the aquifer volume for the specific cases of (a) thin aquifers in flat straight hillslopes, (b) thick aquifers in flat convergent and divergent hillslopes, (c) aquifers in steep convergent and divergent (d) hillslopes and aquifers with a seepage area (Figure $3 \mathrm{a}-\mathrm{d}$ ). The impact of saturation excess overland flow is explored for the exponential model.

\subsection{Thin aquifers in flat straight hillslopes}

The first analytical solution is developed for flat and straight hillslopes $\left(\Theta=0 \%, C_{W}=1\right)$ (Figure 3a). Assuming that head variations with depth are much smaller than in the horizontal direction, the hydraulic head $H(x)$ is integrated over the vertical, as given by the equation of Dupuit-Forchheimer (Dupuit, 1863):

$$
\frac{H(x / L)}{L}=\sqrt{\frac{R}{K}} \cdot \sqrt{\frac{2 x}{L}-\left(\frac{x}{L}\right)^{2}-1+\lambda^{2}}
$$

where

$$
\lambda=\sqrt{1+\frac{K}{R}\left(\frac{H_{0}}{L}\right)^{2}}
$$

Solving the transport equation, the transit time can be expressed as a function of the distance to the river $x$ as (Chesnaux et al., 2005):

$$
t(x)=\frac{\Phi L}{\sqrt{K R}} \lambda\left[f\left(\frac{1-\frac{x}{L}}{\lambda}\right)-f\left(\frac{1}{\lambda}\right)\right]
$$

where $f$ is the function defined by:

$$
f(u)=\ln \left(\frac{1}{u}+\sqrt{\frac{1}{u^{2}}-1}\right)-\sqrt{1-u^{2}} .
$$

Apart from the normalization factor for time $\Phi L / \sqrt{K R}$, transit times depend only on the dimensionless parameter $\lambda$. The moments of the transit time and the coefficient of variation are obtained by numerically integrating equation (14) using the quadrature methods of the SciPy Python package based on the Fortran library QUADPACK (Piessens et al., 1983; Virtanen et

This article is protected by copyright. All rights reserved. 
al., 2020). Because it is dimensionless, the coefficient of variation only depends on $\lambda$ according to the following expression:

$$
C V=\sqrt{\frac{\int_{0}^{1}\left[f\left(\frac{1-\frac{x}{L}}{\lambda}\right)-f(\lambda)\right]^{2} d\left(\frac{x}{L}\right)}{\left[\int_{0}^{1}\left(f\left(\frac{1-\frac{x}{L}}{\lambda}\right)-f(\lambda)\right) d\left(\frac{x}{L}\right)\right]^{2}}-1 .}
$$

The barycenter of the aquifer volume is expressed analytically as:

$$
\frac{\xi}{L}=\frac{\int_{0}^{1} \frac{x}{L} \frac{H(x / L)}{L} d\left(\frac{x}{L}\right)}{\int_{0}^{1} \frac{H(x / L)}{L} d\left(\frac{x}{L}\right)}=1+\frac{\frac{\lambda^{2}}{3}\left[\left(1-\frac{1}{\lambda^{2}}\right)^{3 / 2}-1\right]}{\frac{1}{2} \sqrt{1-\frac{1}{\lambda^{2}}}-\frac{\lambda}{2} \sin ^{-1}\left(-\frac{1}{\lambda}\right)} .
$$

The results (Figure 3e) show that $C V$ depends linearly on $\xi$ :

$$
C V\left(C_{W}=1, \xi / L\right)=1+\alpha\left(\frac{\xi}{L}-\frac{1}{2}\right)
$$

with the slope $\alpha$ approximatively equal to 2.59 . This linear dependence is a compelling result. It cannot be explained by the broad difference of expressions of the coefficient of variation $C V$ and of the barycenter of the aquifer volume $\xi$ (Equations (16) and (17)). It reveals that, in this specific configuration, the distribution of the aquifer volume in the hillslope as characterized by its barycenter is an excellent proxy of the transit time variability described by $C V$. $C V$ evolves linearly from 1 to 1.2 with $\xi / L$ ranging from 0.5 to 0.58 . The minimal value is obtained for a constant thickness aquifer case with a marginally varying head corresponding to an exponential distribution $(C V=1)$ and a barycenter of the aquifer volume exactly at mid-slope $(\xi / L=1 / 2)$. $C V$ increases when the volume tends to be located some more uphill.

\subsection{Thick aquifers in flat convergent and divergent hillslopes}

In such a case (Figure $3 b$ ), the variations of the hydraulic head $H$ are limited because of the high transmissivity (thick highly conductive aquifer). As the aquifer thickness is relatively constant, we assume that the TTD is exponential (Haitjema, 1995). The assumption holds for convergent, straight and divergent hillslopes. Within the analytical development (Leray et al., 2019), this is straightforwardly related to the evolution of the surface of recharge from the river

This article is protected by copyright. All rights reserved. 
to the hillslope divide exactly compensated by the surface of filtration orthogonal to the flow direction within the aquifer. The standard deviation being equal to the mean, the coefficient of variation is equal to 1 . The barycenter of the aquifer volume is given by the convergence or divergence ratio of the hillslope $\left(C_{\mathrm{W}}\right)$ :

$$
\frac{\xi_{E}}{L}=\frac{C_{W}+2}{3 C_{W}+3}
$$

the subscript $E$ standing for exponential. The barycenter of the aquifer volume varies from $2 / 3$ for highly convergent hillslope (small $C_{W}$ ) to $1 / 3$ for highly divergent hillslopes (large $C_{W}$ ). This approximation indicates that the convergence-divergence ratio $C_{W}$ controls independently from $\xi$ but not $C V$. With the previous analytical solution, it indicates that $C V$ depends both on $\xi$ and $C_{W}$.

\subsection{Aquifers in steep convergent and divergent hillslopes}

The third analytical development is obtained for steep hillslopes (Figure 3c). The aquifer shape is assumed to be trapezoidal, on the basis of the linear model (IAEA, 2006; Małoszewski \& Zuber, 1982) with a saturated thickness $H$ linearly evolving with $x$ following the kinematic wave approximation :

$$
H(x)=H_{0}\left(1-\frac{x}{L}\right)
$$

The flow rate $Q(x)$ is expressed thanks to the kinematic wave approximation of Darcy's equation (Sabzevari et al., 2010; Troch et al., 2002):

$$
Q(x)=-K \frac{S(x)}{\Phi} \frac{\partial z}{\partial x}=-K \frac{S(x)}{\Phi} \tan \Theta
$$

where $z$ is the elevation of the bedrock. In this case, we consider a constant slope along the model: $\partial z / \partial x=\tan \Theta$.The saturated thickness of the aquifer $S(x)$ is defined as:

$$
S(x)=\Phi H(x) W(x)
$$

. The derivative of the transit time is obtained with respect to the ratio of the soil moisture storage to the flow rate:

$$
\frac{d t}{d x}=\frac{S(x)}{Q(x)}=-\frac{\Phi}{K \tan \Theta}
$$

This article is protected by copyright. All rights reserved. 
The transit time $t(x)$ does no longer depend on the hillslope convergence/divergence. It is expressed after integration of equation (23) by:

$$
t(x)=\frac{\Phi}{K \tan \Theta} x
$$

With the assumption of a uniform recharge, the TTD is uniform between 0 and $\Phi L /(K \tan \Theta)$. By further integrating equation (24), the $k^{\text {th }}$ moment is given by:

$$
<t^{k}>=\left(\frac{\Phi L}{K \tan \Theta}\right)^{k} \int_{0}^{1}\left(\frac{x}{L}\right)^{k} d\left(\frac{x}{L}\right)
$$

leading to:

$$
C V=\sqrt{\frac{1 / 12}{1 / 4}}=\frac{1}{\sqrt{3}}
$$

In this case, similar to the previous exponential distribution case, the coefficient of variation has a fixed value whatever the convergence/divergence structure of the hillslope. The barycenter of the aquifer volume however changes and can be computed using equations (2) and (20):

$$
\frac{\xi_{U}}{L}=\frac{C_{W}+1}{4 C_{W}+2}
$$

the subscript $U$ standing for uniform. The barycenter ranges from $1 / 4$ to $1 / 2$ for convergent to divergent hillslopes.

\subsection{Generalized expression for the coefficient of variation without seepage}

Based on the three analytical solutions (18), (19) and (27), a general formulation of $C V$ can be proposed for any hillslope without seepage area:

$$
C V_{U}\left(C_{W}, \xi / L\right)=1+\alpha\left(\frac{\xi-\xi_{E}\left(C_{W}\right)}{L}\right)
$$

with

$$
\alpha=\frac{\frac{1}{\sqrt{3}}-1}{\xi_{U}\left(C_{W}\right) / L-\xi_{E}\left(C_{W}\right) / L} .
$$

$\alpha$ is approximatively equal to 2.53 when $C_{W}=1$ in close agreement with $\alpha=2.59$ obtained in the case of the thin aquifer in flat straight hillslopes (section 3.1). Both values are similar despite the strong differences between the assumptions of the three analytical solutions.

This article is protected by copyright. All rights reserved. 
Equation (28) assumes a linear control of $C V$ by $\xi$ generalized from the first analytical solution (Equation (18)), an assumption that will be extensively tested on the general hillslope structures in section 4.

\subsection{Hillslopes with a seepage area}

The last case (Figure 3d) is obtained for a water table intersecting the surface over an area $A_{S}$ where recharge is transferred to the river as saturation excess overland flow. The TTD is made up of two modes. The first one corresponds to the surface excess overland flow with a characteristic time essentially controlled by surface flows that much faster than any transfer underground. It will be approximated by a transit time of 0 resulting in 0 mean and variance $\left(\langle t\rangle_{1}=0 ; \sigma_{1}^{2}=0\right)$. It counts for a proportion $A_{S} / A$ of the overall flow with the reasonable approximation that the seepage area is mostly an outflow zone (Bresciani et al., 2014). The second mode corresponds to the times required for transfer through the aquifer. It accounts for $1-A_{S} / A$ of the recharge. Its mean $\langle t\rangle_{2}$ is derived from the expression of the mean of a binary distribution, knowing that the mean transit time of the full distribution $\langle t\rangle$ is given by equation (9)Error! Reference source not found.:

$$
\langle t\rangle_{2}=\frac{\langle t\rangle}{1-A_{S} / A}
$$

Two assumptions can be tested to derive the variance $\sigma_{2}^{2}$. In the first one, $\sigma_{2}^{2}$ is assumed equal to the variance of the TTD for hillslopes without a seepage area $\left(A_{S} / A=0\right)$ obtained with the same other parameters. It is a strong assumption underpinned by the shift of the underground distribution in the presence of a seepage zone. The assumption is expected to break down for wide seepage zones. In this case, the variance of the full dispersion $\sigma^{2}$ can be expressed as:

$$
\sigma^{2}=\sigma_{2}^{2}\left(1-A_{S} / A\right)+\langle t\rangle^{2} \frac{A_{S} / A}{1-A_{S} / A}
$$

and the coefficient of variation is derived using equations (10)Error! Reference source not

found., (30) and (31) as:

$$
C V_{1}\left(C_{W}, \xi / L, A_{S} / A\right)=\sqrt{\left(1-A_{S} / A\right)\left[C V_{U}\left(C_{W}, \xi / L\right)\right]^{2}+\frac{A_{S} / A}{1-A_{S} / A}}
$$

where $C V_{U}\left(C_{W}, \xi / L\right)$ is the coefficient of variation obtained for the same parameters without any seepage area. This formulation extends the approximation of the coefficient of variation from the case without any seepage to cases with seepage on the basis of the binary distribution

This article is protected by copyright. All rights reserved. 
and the conservation of variability of the subsurface mode. The relation between $A_{S} / A$ and $R / K$ can be related through the characterization of the distance $L_{A_{S}}$ from the river over which the aquifer is outcropping (seepage zone) (Figure 3e). At the onset of the seepage zone, the flux recharged uphill in the aquifer is equal to the flux through the aquifer at $x=L_{A_{S}}$ (Bresciani et al., 2014):

$$
W\left(L_{A_{S}}\right) H_{0} K \theta=R\left(A-A_{S}\right)
$$

assuming that the thickness of the aquifer is similar to that of the river. Using equation (2) to express $W\left(L_{A_{S}}\right), A_{S} / A$ can be expressed as a function of $R / K$ :

$$
\frac{A_{S}}{A}=1-\frac{K}{R} \frac{2 W\left(L_{A_{S}}\right)}{W_{L}+W_{0}} \frac{H_{0} \theta}{L} .
$$

It can alternatively be assumed that the coefficient of variation of the underground contribution with seepage is equal to the coefficient of variation without seepage. Following the same type of developments as in the previous case, the coefficient of variation can be derived as:

$$
C V_{2}\left(C_{W}, \xi / L, A_{S} / A\right)=\sqrt{\frac{1}{\left(1-A_{S} / A\right)}\left[C V_{U}\left(C_{W}, \xi / L\right)\right]^{2}+\frac{A_{S} / A}{1-A_{S} / A}}
$$

Equations (32) and (35) rely on the previous assumptions, and namely, the linear dependency of $C V$ and $\xi$ in the absence of seepage, the validity of the head profiles for the exponential and uniform distributions, and the conservation of the variance or of the coefficient of variation of the subsurface contribution in the presence of seepage. Equations (32) and (35) organize the effect of the parameters $C_{W}, \xi$ and $A_{S} / A$ on the coefficient of variation $C V$ assuming implicitly that the other parameters $K / R, H_{0} / L$ and $\Theta$ only affect $C V$ through $\xi$ and $A_{S} / A$ and not independently.

This article is protected by copyright. All rights reserved. 


\section{Numerical determination of TTDs for the general synthetic and natural hillslopes}

We assessed the relevance of the analytical developments of the previous section to describe the coefficient of variation, specifically the relevance of equations (28), (32) and (35). Based on 378 synthetic hillslopes we explore a wide range of hillslope configurations by changing the values of the model parameters $C_{W}, K / R, H_{0} / L$ and $\Theta$ (Table 1$)$. We successively evaluated 189 cases without and with seepage to assess both the analytical expressions and the assumptions on which they rely. The objective was also to determine to which extent the location of the center of mass of the aquifer and the proportion of seepage control the coefficient of variation and, more generally, the shape of the TTD. We eventually scale up our study to the natural shallow aquifer example (in section 4.3).

\subsection{Control of the coefficient of variation $C V$ by the barycenter of the aquifer volume $\xi$ in the absence of seepage.}

The barycenter of the aquifer $\xi$ and the coefficient of variation $C V$ are represented with respect to the normalized head profile and the probability distribution function for three of divergent hillslopes (Figure 4a). As for the analytical development in Figure $3 \mathrm{e}, C V$ is linearly proportional to $\xi$. In the first case (top row) obtained for small values of $H_{0} / L$ and $\Theta$, the hydraulic head has a marked parabolic profile, similar of the flat straight hillslope with small $H_{0} / L$ (Figure $\left.4 \mathrm{~b}\right)$. The barycenter of the aquifer volume is close to the river $(\xi / L=0.41)$ because of the diverging shape of the hillslope. The TTD has higher quantities for the smallest and largest times than the exponential distribution (red curve above the dashed black curve, Figure 4c). The parabolic head profile speeds up flows close to the outlet while it slows them down on the top of the hillslope. The diverging structure of the hillslope also contributes to the relative large proportion of the shorter times due to the higher recharge close to the river. The first effect is especially strong as the aquifer remains thin. For thick aquifers for which the head profile becomes more linear (Figure 4d), the TTD becomes similar to the exponential distribution as expected even with a non-zero but small slope $(\Theta=1 \%)$ (Figure 4e). In the third case of a steep diverging hillslope, the water accumulates downhill (Figure 4f) and the TTD tends to a uniform distribution (Figure $4 \mathrm{~g}$ ) as observed with the linear model (Cook \& Böhlke, 2000). Although the TTD is approximately uniform, the water accumulates more downhill than expected with a very low aquifer thickness uphill. It significantly differs from

This article is protected by copyright. All rights reserved. 
the linear head profile expected in the third analytical solution. As a consequence, the value of $\xi / L(0.22)$ is notably smaller than the value $(0.26)$ predicted by equation $(27)$.

These first results are confirmed by the systematic exploration of the parameter space for the other simulated hillslopes (convergent and divergent). The coefficient of variation $C V$ increases linearly with the barycenter of the aquifer volume $\xi$. Equation (28) is closely consistent with the numerical results as long as the barycenter of the aquifer volume in the uniform case $\xi_{U}$ is taken as its numerical estimate rather than as its analytical approximation given by equation (27). Numerical estimates of $\xi_{U}$ are obtained by minimizing the least-square difference between numerical results and the approximation given by equations (28) and (29) in which $\xi_{U}$ is taken as a fitting parameter. Numerical results obtained for the full range of convergent, straight and divergent hillslopes show that $\xi_{U}$ is approximatively equal to $\xi_{E}+L / 6$ with a mean deviation of $15 \%$. The relevance of equation (28) is further assessed by the insert of Figure 5 showing the numerical results versus the analytical approximations of $C V$. The mean and variance of their differences are limited to -0.0058 and 0.0172 respectively, equal to $1 \%$ and $3 \%$ of the range of $C V$ (0.6-1.2). The linear dependence of $C V$ on $\xi$ is again a striking result. The linear coefficient only depends on the convergent-divergent structure of the hillslope. $\xi$ is a good proxy of $C V$ when the hillslope convergent or divergent shape $C_{W}$ is known. The influence of the other parameters $K / R, H_{0} / L$ and $\Theta$ on $C V$ is well captured by $\xi$.

We further investigate the relevance of $\xi$ and $C_{W}$ to characterize the shape of the TTD beyond its coefficient of variation. Beyond some limited differences, the shape of the distributions remains similar for each of the value of $C V$ (Figure 6) showing that $C V$ is a good descriptor of the TTD. Note that the shape of the TTDs more widely differs towards the uniform distribution $(C V<1)$ than towards the power-law distribution $(C V>1)$. It is also reflected by the larger interval of values of CV below 1 ([0.6;1]) than above 1 ([1;1.2]) (Figure 5).

Therefore, we conclude that equations (28) and (29) closely characterize the coefficient of variation without any seepage. At any given hillslope shape characterized by $C_{W}$, the repartition of water as measured by $\xi$ is a good proxy of $C V$ and of the shape of the TTD.

\subsection{Dependence of the coefficient of variation $C V$ on the seepage area}

Simulations with seepage were performed with the additional upper drainage boundary condition to model the development of the seepage zone as a result of the interception of the water table by the surface... The extension of the seepage zone has several effects on the TTD. It increases the percentage of saturation excess overland flow $A_{S} / A$ and modifies the TTD of

This article is protected by copyright. All rights reserved. 
the subsurface component resulting in more complex shapes. As the extent of the seepage zone relative to the hillslope area $\left(A_{S} / A\right)$ increases from $10 \%$ to $70 \%$ (Figure 7c), the TTD of the subsurface contribution shifts from a closely exponential distribution to a more complex shape (Figure $7 \mathrm{~b}$ ) and the coefficient of variation increases without any marked change in the barycenter of the aquifer volume $\xi$ (Figure 7a).

Without any significant change in $\xi / L$, modifications of the shape of the transit time distribution are mostly driven by the seepage area. As expected, larger seepage areas (from hillslope bottom to top) increase the probability of occurrence of short transit times (infiltration excess overland flow (not shown on Figure 7)) and of times much larger than the mean. The distribution does not however follow the expected shape of the confined cases from which the first development of section 3.5 is inspired. The distribution is rather deformed with a remaining first peak at smaller times $(t / \tau<1)$ and a longer uniform-trending tail (Figure 7, right column). The first peak is coming from the flow lines outcropping in the seepage zone (Figure 8). The flow lines are relatively short remaining close to the surface where velocity remains high (blue lines on Figure 8). Water gets in and quickly out. The probability of these short times tends to increase as also observed for natural catchment shapes. This is explained by an intensification of the circulation with the rise of the groundwater level (Kaandorp et al., 2018). The presence of the seepage guarantees the existence of this short-time peak. The second trailing part of the distribution mostly corresponds to the flow lines all the way from a recharge upstream from the seepage zone to a discharge area in the river (red and orange lines on Figure 8). In addition to the longer length of the flow lines, velocity is significantly reduced by the lateral and depth extent of the seepage zone.

A more systematic analysis of $C V$ against $\xi / L$ for convergent, straight and divergent hillslopes confirms that larger seepage areas do not significantly modify $\xi$ but strongly increase $C V$ (Figure 9). Even though the fundamental assumption on which the derivation of equation (32) relies does not hold (the distribution shape being modified), the deviation between the analytical and numerical results is small (Figure 9). The differences between the analytical expression (32) and the numerical results have a mean and standard deviation of 0.0627 and 0.15 , which given the range of variation of $C V$ between 0.5 and 2.225 , represent respectively $3.5 \%$ and $8.5 \%$ of the range.

As a partial conclusion at this stage, the development of the seepage zone appears to have a more complex effect on the subsurface contribution to the TTD than expected. Its shape significantly evolves from a classical exponential behavior to a two-sided shape following the

This article is protected by copyright. All rights reserved. 
organization of the circulations in shallower flows to the seepage zone and deeper flows to the river. For any convergent or divergent hillslope shape characterized by $C_{W}, C V$ is well approached by $\xi$ and $A_{S} / A$ as expressed by equation (32). Without a strong basis, this agreement is however not guaranteed to hold for any other type of systems.

\subsection{Development of seepage areas in natural hillslopes and its impact on the coefficient of variation $\mathrm{CV}$}

Flow and transport were modeled for the real hillslope using the same approach defined in section 2.2 with evolving aquifer thickness and seepage. Figure 10 shows in colors some of the flow lines and in black the seepage zones for real and smoothed topography. In the real case, the seepage zones are highly clustered downstream at low points in the topography (Figure 10a). The drainage condition applied at the surface efficiently transports the groundwater flows in the steep depressions limiting the development of the zone of seepage. The extent of the seepage zone $A_{\mathrm{S}} / A$ sharply increases from $6 \%$ in the rough case to $27 \%$ for the smooth case without any marked difference in the organization of flow pathways. Flow lines are essentially similar (Figure 10). The downhill low area remains also the main outflow zone as expected in natural cliff systems. In the real case, some flow lines outcrop uphill from the main seepage zone in localized areas. Overall, outflow zones are smaller and less clustered for the real case.

Figure 11 confirms the importance of the extent of the seepage zone $A_{S} / A$ for the variation of the TTD. Once the hillslope has been defined, $A_{S} / A$ fully explains the coefficient of variation $C V$. The relation between $A_{\mathrm{S}} / A$ and $C V$ however strongly depends on the shape of the hillslope, as well as on the resolution of the topographic data. Both the ranges of values of $A_{\mathrm{S}} / A$ and $C V$ are quite different. For the same recharge over hydraulic conductivity rates $R / K=[0.00025-$ 0.005], $A_{\mathrm{S}} / A$ is limited to 0.1 for the real case while it goes up to 0.5 in the smooth case. $C V$ is in turn only 1.74 in the real case where it goes up to 2.05 for the smooth case. The extent of the seepage zone $A_{\mathrm{S}} / A$ increases the saturation excess overland flow, the proportion of short times and the relative variability of the TTD. Both trends remain much steeper than the analytical estimates obtained with synthetic hillslopes. The main difference to the analytical estimate obtained with a uniform slope comes from the effect of the cliff limiting both the extension of the seepage zone and the differentiation in the TTD distribution between short rapid and long slow flow pathways.

The values of $C V$ and the TTD for the natural hillslopes (Figure 12, blue and red lines) strongly differ from the TTD of the equivalent hillslope having the same average slope (dotted-dashed

This article is protected by copyright. All rights reserved. 
grey line). The percentage of saturated area $A_{S} / A$ goes up to $78 \%$ for the uniform hillslope, respectively 3 and 12 times larger than for the smooth and rough hillslope structures. It demonstrates that the extension and organization of the seepage zone are critical for the determination of the groundwater contribution to the TTD. In the presence of seepage zone, the structure of the topography should be considered as a dominant factor controlling the groundwater transit times. Comparatively, the TTD of the rough and smoothed topography cases remain similar even at high smoothing scales for not too large forcing terms $R / K$ (Figure 12 , blue and red curves). The results also show that, once the topographic structure is fixed (smoothed natural, rough natural, synthetic hillslope with constant slope), the extent of the seepage zone $A_{\mathrm{S}} / A$ determines the TTD variability. The precise relation between the TTD variability and the extent of the seepage zone depends on the organization of the seepage areas in the hillslope. Determination of this relation and its dependency on the geomorphological structures require complementary investigations as discussed further in section 5.2.

This article is protected by copyright. All rights reserved. 


\section{Discussion}

The results show that, for the investigated hillslope structures, the coefficient of variation $C V$ of the TTD is determined by the distribution of the groundwater volume with respect to the river, as represented by its barycenter $\xi$ and by the organization and extent of the saturated area $A_{\mathrm{S}} / A$. Compared to the initial formulation of the problem, it is not so much the reduction of the number of degrees of freedom from the four initial ones $\left(C_{\mathrm{W}}, H_{0} / L, R / K, \Theta\right)$ to three $\left(C_{\mathrm{W}}, \xi\right.$, $A_{\mathrm{S}} / A$ ) than the nature of the controlling factors that are important. We argue that $\xi / L$ and $A_{\mathrm{S}} / A$ can be more directly estimated from field observations than $H_{0} / L, R / K$ and $\Theta$ to estimate the variability of the TTD. The relative position of the water within the aquifer and the saturated area are also integrated features at aggregated scales, which filter some of the details of the geomorphological landscape structures.

\subsection{Relevance and determination of the barycenter of the aquifer volume $(\xi / L)$}

In the absence of seepage, the coefficient of variation of the TTD is directly given by $\xi / L$ for all synthetic hillslope structures analyzed here. While it is well know that the mean transit time is directly related to the aquifer volume (Cornaton \& Perrochet, 2006; Haitjema, 1995), we show that the variability of the transit times is controlled by the spatial distribution of groundwater with respect to the river, as identified by its barycenter $\xi$. This is a new and compelling result, which highlights how important it is to anticipate potential deviations from the exponential transit times distribution model that are classically used for shallow aquifers under uniform recharge and in the absence of seepage. Any divergence from the exponential distribution results from the spatial distribution of aquifer thickness from the bottom up to the top of the hillslope. Decreasing saturated thicknesses uphill lead to more uniform TTDs with lower variability. Increasing thicknesses of the saturated area uphill results in more variable Gamma-like TTDs. Beyond the characterization of the overall volume required for the mean transit time, the coefficient of variation requires more advanced information on the architecture of the flow paths and saturated thickness.

Even though $\xi$ cannot be measured directly in the field, it can be estimated in several ways. Its evaluation for flat and steep aquifers given by equations (19) and (27) indicate that it can be assessed without the detailed knowledge of the saturation. More precisely, equations (28) and (29) show that $C V$ is directly given by the relative distance between the barycenter of the saturated groundwater volume $\xi$ and the barycenter obtained with a uniform saturation $\xi_{E}$ compared to the full width of the interval $\xi_{E}-\xi_{U}$ expressed quantitatively as $1-$

This article is protected by copyright. All rights reserved. 
$\left(\xi-\xi_{E}\right) /\left(\xi_{U}-\xi_{E}\right)$. It can be more broadly interpreted as the saturated thickness of the aquifer relative to the constant saturated thickness leading to $\xi_{E}$ (Figure $3 b$ ) normalized by the width of the interval $\xi_{E}-\xi_{U}$, which is relatively constant and equal to around $L / 6$. For convergent or divergent hillslopes, such as the ones presented here, the relative filling can be determined by simple modelling approaches either analytical, semi-analytical or numerical (Harman, 2015). For more complex hillslope structures, the digital terrain model and some assumption on the bedrock structure should be integrated to capture the geomorphological control on the convergence-divergence rate $C_{W}$. For example, for crystalline basements, assumptions on the structure of the weathered zone might be obtained from geophysics (Clair et al., 2015), from local databases (Mougin et al., 2008), from global databases (Shangguan et al., 2017), or from prediction derived from coupled groundwater, erosion and weathering models (Rempe \& Dietrich, 2014). Additional hydraulic and geological information might be integrated to refine the effective location of the water within the aquifer. While the dependence of $C V$ to $C_{W}$ and $\xi$ given by equation (28) is expected to hold globally, the determination of $\xi$ and to a lesser extent of $C_{W}$ might require complementary approximation methods. The results obtained here might then be used in a more qualitative way to assess the deviation of the TTD from the exponential model towards the uniform- or gamma-like models taking $\mathrm{CV}$ as a proxy of the shape of the expected TTD (Figure 13).

Without seepage, the Figure 13 shows that $\xi$ is the main factor controlling the variability in the TTD and needs to be estimated more carefully than for large saturated thicknesses, where the effect of $A_{S} / A$ dominates over $\xi$ on the variability of transit times. However, intermediate cases are expected to be more common, especially in the context of headwater catchment where saturation conditions strongly fluctuate between dry and wet seasons (Rosenberry \& Winter, 1997).

\subsection{Relevance, determination and limitations of the relative saturated area $A_{\mathrm{S}} / A$}

The observed and modeled seepage zone should closely correspond to ensure the relevance of $A_{\mathrm{S}} / A$ in the prediction of the TTD. From the field perspective, seepage both introduces fast transit times and modifies the groundwater contribution to the TTD. The fast transit times come from saturation excess overland flows. The groundwater contribution to the TTD is extended with more shorter times to the seepage zone and more longer times below the seepage zone where flows are reduced. Both depend directly on the extent of the saturated area $A_{\mathrm{S}} / A . A_{\mathrm{S}} / A$ can be estimated based on direct observations of the wet areas and of their extension. Such

This article is protected by copyright. All rights reserved. 
information is available at places through local expertise and recurrent observations both in dry and wet seasons from which a mean saturation could be estimated. The information might be also indirectly deduced from remote sensing techniques and vegetation mapping (Franks et al., 1998; Merot et al., 2003).

The modeled $A_{S} / A$ is highly sensitive to the topographic features involved at large scales, as demonstrated by the fundamental differences in TTDs between the natural and synthetic hillslope cases, and at smaller scales with its dependence on the resolution of the digital elevation model. $A_{\mathrm{S}} / A$ is only conditioned by the subsurface flows, under the assumption of non-limiting surface drainage, which could otherwise limit the extension of the seepage zones. This is mainly the case for the rough topography for which local small depression zones have a strong impact by attracting flow lines without much extension of the seepage zones. The saturated area is sharply reduced compared to the smooth topography case while it keeps the same overall distribution. Therefore, comparison between observed and modeled saturated zones should not only be based on their average extent but also on their spatial structure.

The investigated synthetic and natural hillslope cases display marked differences in the structure of the seepage zones. In the synthetic converging and diverging cases with uniform slope, the seepage area progresses monotonically uphill with increasing recharge to hydraulic conductivity ratios. Even though the extent of the seepage zone from the river leads to some variations between the center and the hillslope divides on the sides, it remains essentially a 1D problem that can be handled with an equivalent hillslope formalism (Troch et al., 2003). This is especially the cases for smooth natural hillslopes.

In the case of more complex topographies such as the one introduced in section 2.2 and studied in section 4.3, the structure of the seepage zone is controlled by other structures like the cliff. In other cases, it may develop irregularly uphill through local depressions serving as extensions of the stream network making the problem fully 2D. In such cases, the coefficient of variation is not only determined by the extent of the seepage zone but also by its structure. Complementary metrics should be determined to capture the structural features controlling the subsurface transit times.

Determination of complementary indices might be inspired from spatially distributed metrics classically used in hillslope hydrology to characterize the spatial distribution of the seepage area as well as the distribution of transit times. Seepage areas have been related to the Topographic Wetness Index (Grabs et al., 2009; Güntner et al., 2004), a distributed indicator based on the ratio of the upstream contributing area to the slope (Beven \& Kirkby, 1979;

This article is protected by copyright. All rights reserved. 
Hrachowitz et al., 2010). Generalizations have been proposed to account for the climatic conditions in the climato-topographic index (Infascelli et al., 2013; Remondi et al., 2019; Seeger \& Weiler, 2014) and for the aquifer transmissivity condition in the soil topographic index (Mukherjee et al., 2013). Transit times have also been expressed for surface transfers as a function of the flow path distance to the flow gradient to the stream network (Dunn et al., 2007; Gabrielli et al., 2018; Lane et al., 2020; McGuire et al., 2005). Such indices might be useful to characterize the dependence of transit times on topographic structures.

\subsection{Implications for the interpretation of groundwater age data and the inference of TTDs}

We discuss how the presented results can practically be used to interpret groundwater age and infer TTDs from field data. Environmental tracers such as dissolved gases (CFCs, SF6, tritium/3He) and radioactive isotopes ${ }^{3} \mathrm{H},{ }^{14} \mathrm{C},{ }^{39} \mathrm{Ar},{ }^{36} \mathrm{Cl},{ }^{85} \mathrm{Kr}$ have been used to characterize the residence and transit times in groundwater systems (Alvarado et al., 2005, 2007; Bauer et al., 2001; Carreira et al., 2011; Chambers et al., 2019; Chen et al., 2011; Cook \& Herczeg, 2000; Massoudieh et al., 2012; Newman et al., 2010; Stotler et al., 2009). Taken alone, each of these tracers only provides a partial vision of the TTD limited to the range of transit times they cover. When several tracers are available, covering different age ranges, shape-free distribution models (Engdahl \& Maxwell, 2014) should be used to combine the flexibility of the approach, the relevance of the emerging distribution models and the information capacities of the tracers considered (Massoudieh et al., 2014; McCallum et al., 2014).

When only limited groundwater age data are available without significant differences between them, as it is the case for tracers that are used to characterize recent circulations (typically $<50$ years), the problem remains largely under-constrained. Physically-based TTDs resulting from quantitative representations of groundwater flows can be used to account for water mixing and tracer dispersion within and between formations (Broers, 2004; Eberts et al., 2012; Ju et al., 2021; Kolbe et al., 2016; Leray et al., 2012). When the development of a fully-distributed numerical model is out of reach, Lumped Parameters Models (LPMs) can be used as an alternative to fill up the gaps between and beyond tracers (McCallum et al., 2015; Underwood et al., 2018; Zuber et al., 2011). In such cases, LPMs must be chosen externally-independently of the tracers - with mostly qualitative information. They are used to approach the TTD (IAEA, 2006; Małoszewski \& Zuber, 1982; Visser et al., 2013; Zuber et al., 1986) and constrain part of the physical determinism of geochemical and ecological processes (Abbott et al., 2016; Green et al., 2016; Koh et al., 2018; Pinay et al., 2015).

This article is protected by copyright. All rights reserved. 
The TTDs characterized here provide reference LPMs for the investigated category of hillslopes with uniform slopes. They are parameterized by the mean and their coefficient of variation of the TDD. They include several models including first the exponential, uniform and bimodal models on which they rely. They are consistent with several other analytical solutions developed for sloping aquifers where the aquifer thickness evolves with the distance to its outlet (Etcheverry, 2001; Kirchner et al., 2000; Leray et al., 2016, 2019; Małoszewski \& Zuber, 1982; McGuire \& McDonnell, 2006). When the aquifer volume decreases towards the stream, the TTD broadens and becomes similar to the Gamma distribution models with a shape factor near 0.5 (Kirchner et al., 2000; McGuire \& McDonnell, 2006). This is typically the case of incised hillslopes where the river limits the depth of the weathered zone (Leray et al., 2018). On the other end of the spectrum, when the aquifer volume increases towards the outlet, as for some alluvial aquifers, the TTD becomes more uniform (IAEA, 2006; Małoszewski \& Zuber, 1982; Zuber et al., 1986).

Characterizing the TTD moments from indices like $\xi$ and $A_{\mathrm{S}}$ might additionally be used to assess transit time properties at large scale for shallow aquifer systems. What has been done on mean transit times from flow simulations (Basu et al., 2012) might be extended to assess transit time variability from hillslope to catchment and regional scales (Troldborg et al., 2007, 2008). To further improve the representation of the transit time variability, more general hillslope structures might be analyzed to account for slope variations, like in concave or convex hillslopes (Evans, 1980; Sabzevari et al., 2010) or in even more complex sigmoidal shapes like the natural hillslope example. With the rapidly evolving hybrid modeling approaches involving physical models and statistical learning methods (Reichstein et al., 2019), the generic correlations might be further used and refined in combination with extensive numerical simulations to regionalize TTDs from mappable physical features (Fienen et al., 2018; Starn \& Belitz, 2018).

This article is protected by copyright. All rights reserved. 


\section{Conclusions}

We have investigated how the distribution of groundwater volume affects the transit time under steady state recharge at the hillslope scale. Our analysis was based on synthetic uniform convergent, straight and divergent hillslope, with a constant slope and a uniform recharge. Subsurface flows were modeled by the classic diffusion equation. When the flow exfiltrates at the saturated discharge area, water is directly transferred over the stream with a time considered much smaller than the characteristic transport time in the subsurface. The hillslope model is characterized by four dimensionless parameters, which are its convergence/divergence ratio, its slope, the ratio of the applied recharge to hydraulic conductivity and the ratio of its depth to its characteristic length. Flows and transit times were determined numerically in 3D using the MODFLOW and MODPATH software suite. The variability of the TTD described by its coefficient of variation (ratio of the standard deviation to the mean) is controlled by the mean distance of the groundwater volume to the river normalized by the hillslope length $(\xi / L)$ and by the proportion of seepage area relative to the total area $\left(A_{\mathrm{S}} / A\right)$ for any convergent or divergent ratio $\left(C_{W}\right)$.

In the absence of seepage, the coefficient of variation scales linearly with $\xi / L$ in agreement with analytical developments of the specific cases of (1) thin aquifers in flat straight hillslopes, (2) thick aquifers in flat convergent and divergent hillslopes, (3) aquifers in steep convergent and divergent hillslopes. This remarkable result might offer simple ways to assess the variability of transit times at large scales and for remote areas. However, it should be confirmed on a broader range of synthetic and naturel hillslope structures and extended to heterogeneous aquifers. Heterogeneities in the aquifer thickness induced by changes in hydraulic conductivity or the bedrock structure, are known to be important factors controlling transit times and their variability. They modify the distribution of head and saturation in the aquifer. Smaller hydraulic conductivities let travel times increase through thicker aquifers. The results obtained here might first be extended to some bounded heterogeneities considering the hillslope as an effective model with adapted parameters. It follows the same rationale as that of Luther and Haitjema (1998) according to which the renewal time (volume over areal recharge) remains relevant as long as the ratio of depth over local recharge does not display any marked trend.

When seepage occurs, the TTD is significantly modified. Additionally, to the rapid transfer of overland flows, the groundwater contribution to the TTD becomes bimodal. The first mode comes from rapid circulations close to the seepage zone. The second mode represents deeper

This article is protected by copyright. All rights reserved. 
circulations going from a recharge area more uphill to the river below the seepage zone. The groundwater contribution to the distribution cannot be deduced from the results obtained in the absence of seepage. The coefficient of variation of the TTD however remains a simple function of the relative seepage extent $\left(A_{S} / A\right)$. A complementary analysis performed on a natural hillslope structure coming from a crystalline basement in Normandy (France) shows that the TTD depends both on the seepage extent and on its organization in the hillslope, including both local and global topographic structures.

\section{Acknowledgments}

This work was supported by the RIVAGES Normand 2100 Project. Sarah Leray acknowledges funding from the project CONICYT/Fondecyt de Iniciación 11170380.

We thank Henk Haitjema for insightful comments and for pointing out that equation (17) could be integrated analytically.

Data were not used for this research.

This article is protected by copyright. All rights reserved. 


\section{References}

Abbott, B. W., Baranov, V., Mendoza-Lera, C., Nikolakopoulou, M., Harjung, A., Kolbe, T., et al. (2016). Using multi-tracer inference to move beyond single-catchment ecohydrology. $\quad$ Earth-Science $\quad$ Reviews, $\quad 160, \quad 19-42$. https://doi.org/10.1016/j.earscirev.2016.06.014

Alvarado, J. A. C., Purtschert, R., Hinsby, K., Troldborg, L., Hofer, M., Kipfer, R., et al. (2005). $36 \mathrm{Cl}$ in modern groundwater dated by a multi-tracer approach $(3 \mathrm{H} / 3 \mathrm{He}, \mathrm{SF} 6, \mathrm{CFC}-12$ and $85 \mathrm{Kr}$ ): a case study in quaternary sand aquifers in the Odense Pilot River Basin, Denmark. Applied Geochemistry, 11. https://doi.org/10.1016/j.apgeochem.2004.09.018

Alvarado, J. A. C., Purtschert, R., Barbecot, F., Chabault, C., Rueedi, J., Schneider, V., et al. (2007). Constraining the age distribution of highly mixed groundwater using ${ }^{39}$ Ar: A multiple environmental tracer $\left({ }^{3} \mathrm{H} /{ }^{3} \mathrm{He},{ }^{85} \mathrm{Kr},{ }^{39} \mathrm{Ar}\right.$, and $\left.{ }^{14} \mathrm{C}\right)$ study in the semiconfined Fontainebleau Sands Aquifer (France): CONSTRAINING THE AGE OF GROUNDWATER. Water Resources Research, 43(3). https://doi.org/10.1029/2006WR005096

Ambroise, B., Beven, K. J., \& Freer, J. (1996). Toward a generalization of the TOPMODEL concepts: Topographic indices of hydrological similarity. Water Resources Research, 32(7), 2135-2145. https://doi.org/10.1029/95wr03716

Appelo, C. A. J., \& Postma, D. (1994). Geochemistry, Groundwater and Pollution. AA Balkema, Brookfield.

Bakker, M., Post, V., Langevin, C. D., Hughes, J. D., White, J. T., Starn, J. J., \& Fienen, M. N. (2016). Scripting MODFLOW Model Development Using Python and FloPy. Groundwater, 54(5), 733-739. https://doi.org/10.1111/gwat.12413

Basu, N. B., Jindal, P., Schilling, K. E., Wolter, C. F., \& Takle, E. S. (2012). Evaluation of analytical and numerical approaches for the estimation of groundwater travel time 
distribution.

Journal

of

Hydrology,

475 ,

65-73.

https://doi.org/10.1016/j.jhydrol.2012.08.052

Bauer, S., Fulda, C., \& Schäfer, W. (2001). A multi-tracer study in a shallow aquifer using age dating tracers $3 \mathrm{H}, 85 \mathrm{Kr}, \mathrm{CFC}-113$ and SF 6 - indication for retarded transport of CFC113. Journal of Hydrology, 21. https://doi.org/10.1016/S0022-1694(01)00381-X

Bear, J. (1972). Dynamics of Fluids in Porous Media. Soil Science, 120(2). Retrieved from https://journals.lww.com/soilsci/Fulltext/1975/08000/Dynamics_of_Fluids_in_Porous _Media.22.aspx

Berne, A., Uijlenhoet, R., \& Troch, P. A. (2005). Similarity analysis of subsurface flow response of hillslopes with complex geometry. Water Resour. Res., 41(9), 10. https://doi.org/10.1029/2004wr003629

Bethke, C. M., \& Johnson, T. M. (2002). Paradox of groundwater age, 4.

Beven, K. J., \& Kirkby, M. J. (1979). A physically based, variable contributing area model of basin hydrology / Un modèle à base physique, 28.

Beven, K. J., \& Wood, E. F. (1983). Catchment geomorphology and the dynamics of runoff contributing areas. Journal of Hydrology, 65(1-3), 139-158. https://doi.org/10.1016/0022-1694(83)90214-7

Bogaart, P. W., \& Troch, P. A. (2006). Curvature distribution within hillslopes and catchments and its effect on the hydrological response. Hydrology and Earth System Sciences, 10(6), 925-936. https://doi.org/10.5194/hess-10-925-2006

Bolin, B., \& Rodhe, H. (1973). A note on the concepts of age distribution and transit time in natural reservoirs. Tellus, 25(1), 58-62. https://doi.org/10.1111/j.21533490.1973.tb01594.x

This article is protected by copyright. All rights reserved. 
Bresciani, E., Davy, P., \& de Dreuzy, J.-R. (2014). Is the Dupuit assumption suitable for predicting the groundwater seepage area in hillslopes? Water Resources Research, 50(3), 2394-2406. https://doi.org/10.1002/2013WR014284

Bresciani, E., Goderniaux, P., \& Batelaan, O. (2016). Hydrogeological controls of water tableland surface interactions: Water Table-Land Surface Interactions. Geophysical Research Letters, 43(18), 9653-9661. https://doi.org/10.1002/2016GL070618

Broers, H. P. (2004). The spatial distribution of groundwater age for different geohydrological situations in the Netherlands: implications for groundwater quality monitoring at the regional scale. Journal of Hydrology, 299(1-2), 84-106. https://doi.org/10.1016/j.jhydrol.2004.04.023

Carreira, P. M., Marques, J. M., Espinha Marques, J., Chaminé, H. I., Fonseca, P. E., Santos, F. M., et al. (2011). Defining the dynamics of groundwater in Serra da Estrela Mountain area, central Portugal: an isotopic and hydrogeochemical approach. Hydrogeology Journal, 19(1), 117-131. https://doi.org/10.1007/s10040-010-0675-0

Chambers, L. A., Gooddy, D. C., \& Binley, A. M. (2019). Use and application of CFC-11, CFC-12, CFC-113 and SF6 as environmental tracers of groundwater residence time: A review. Geoscience $\quad$ Frontiers, $\quad 10(5), \quad 1643-1652$. https://doi.org/10.1016/j.gsf.2018.02.017

Chen, Z., Wei, W., Liu, J., Wang, Y., \& Chen, J. (2011). Identifying the recharge sources and age of groundwater in the Songnen Plain (Northeast China) using environmental isotopes. Hydrogeology Journal, 19(1), 163-176. https://doi.org/10.1007/s10040-0100650-9

Chesnaux, R., Molson, J. W., \& Chapuis, R. P. (2005). An Analytical Solution for Ground Water Transit Time through Unconfined Aquifers. Ground Water, 43(4), 511-517. https://doi.org/10.1111/j.1745-6584.2005.0056.x

This article is protected by copyright. All rights reserved. 
Clair, J. S., Moon, S., Holbrook, W. S., Perron, J. T., Riebe, C. S., Martel, S. J., et al. (2015). Geophysical imaging reveals topographic stress control of bedrock weathering. Science, 350(6260), 534-538. https://doi.org/10.1126/science.aab2210

Condon, L. E., \& Maxwell, R. M. (2015). Evaluating the relationship between topography and groundwater using outputs from a continental-scale integrated hydrology model: EVALUATING GROUNDWATER CONTROLS. Water Resources Research, 51(8), 6602-6621. https://doi.org/10.1002/2014WR016774

Cook, P. G., \& Böhlke, J.-K. (2000). Determining Timescales for Groundwater Flow and Solute Transport. In P. G. Cook \& A. L. Herczeg (Eds.), Environmental Tracers in Subsurface Hydrology (pp. 1-30). Boston, MA: Springer US. https://doi.org/10.1007/978-1-46154557-6_1

Cook, P. G., \& Herczeg, A. L. (2000). Environmental tracers in subsurface hydrology. https://doi.org/10.1007/978-1-4615-4557-6

Cornaton, F., \& Perrochet, P. (2006). Groundwater age, life expectancy and transit time distributions in advective-dispersive systems: 1. Generalized reservoir theory. Advances in Water Resources, 29(9), 1267-1291. https://doi.org/10.1016/j.advwatres.2005.10.009

Cudennec, C., Fouad, Y., Sumarjo Gatot, I., \& Duchesne, J. (2004). A geomorphological explanation of the unit hydrograph concept. Hydrological Processes, 18(4), 603-621. https://doi.org/10.1002/hyp.1368

Cuthbert, M. O., Gleeson, T., Moosdorf, N., Befus, K. M., Schneider, A., Hartmann, J., \& Lehner, B. (2019). Global patterns and dynamics of climate-groundwater interactions. Nature Climate Change, 9(2), 137-141. https://doi.org/10.1038/s41558-018-0386-4

This article is protected by copyright. All rights reserved. 
Doré, F., Dupret, L., Lautridou, J. P., \& Hommeril, P. (1988). Carte géol. France (1/50 000), feuille Granville (172) - Orléans : BRGM. Notice explicative par Doré F., Dupret L., Lautridou J.P., Hommeril P. (1988), 55p.

Dunn, S. M., McDonnell, J. J., \& Vaché, K. B. (2007). Factors influencing the residence time of catchment waters: A virtual experiment approach: RESIDENCE TIME OF CATCHMENT WATERS. Water Resources Research, 43(6). https://doi.org/10.1029/2006WR005393

Dupret, L., Ponvet, J., Lautridou, J. P., \& Hommeril, P. (1987). Carte géol. France (1/50 000), feuille COUTANCES (142) - Orléans: Bureau de recherches géologiques et minières. Notice explicative par Dupret L., Poncet J., Lautridou J.P., Hommeril P. et coll (1989), $58 \mathrm{p}$.

Dupuit, J. (1863). Études théoriques et pratiques sur le mouvement des eaux dans les canaux découverts et à travers les terrains perméables., 354.

Eberts, S. M., Bohlke, J. K., Kauffman, L. J., \& Jurgens, B. C. (2012). Comparison of particletracking and lumped-parameter age-distribution models for evaluating vulnerability of production wells to contamination. Hydrogeology Journal, 20(2), 263-282. https://doi.org/10.1007/s10040-011-0810-6

Engdahl, N. B., \& Maxwell, R. M. (2014). Approximating groundwater age distributions using simple streamtube models and multiple tracers. Advances in Water Resources, 66, 1931. https://doi.org/10.1016/j.advwatres.2014.02.001

Eriksson, E. (1971). Compartment Models and Reservoir Theory. Annual Review of Ecology and Systematics, 2(1), 67-84. https://doi.org/10.1146/annurev.es.02.110171.000435

Etcheverry, D. (2001). Une approche déterministe des distributions des temps de transit de l'eau souterraine par la théorie des réservoirs. Retrieved from http://doc.rero.ch/record/4270

This article is protected by copyright. All rights reserved. 
Etcheverry, D., \& Perrochet, P. (2000). Direct simulation of groundwater transit-time distributions using the reservoir theory. Hydrogeology Journal, 8(2), 200-208.

Evans, I. S. (1980). An integrated system of terrain analysis and slope mapping. An Integrated System of Terrain Analysis and Slope Mapping, (36), 274-295.

Fan, Y., \& Bras, R. L. (1998). Analytical solutions to hillslope subsurface storm flow and saturation overland flow. Water Resources Research, 34(4), 921-927. https://doi.org/10.1029/97WR03516

Fetter, C. W. (2000). Applied Hydrogeology (4th Edition). Prentice Hall.

Fienen, M. N., Nolan, B. T., Kauffman, L. J., \& Feinstein, D. T. (2018). Metamodeling for Groundwater Age Forecasting in the Lake Michigan Basin. Water Resources Research, 54(7), 4750-4766. https://doi.org/10.1029/2017WR022387

Franks, S. W., Gineste, P., Beven, K. J., \& Merot, P. (1998). On constraining the predictions of a distributed model: The incorporation of fuzzy estimates of saturated areas into the calibration process. Water Resources Research, 34(4), 787-797. https://doi.org/10.1029/97WR03041

Gabrielli, C. P., Morgenstern, U., Stewart, M. K., \& McDonnell, J. J. (2018). Contrasting Groundwater and Streamflow Ages at the Maimai Watershed. Water Resources Research, 54(6), 3937-3957. https://doi.org/10.1029/2017wr021825

Gburek, W. J., \& Folmar, G. J. (1999). Patterns of contaminant transport in a layered fractured aquifer. Journal of Contaminant Hydrology, 37(1-2), 87-109. https://doi.org/10.1016/s0169-7722(98)00158-2

Gleeson, T., Befus, K. M., Jasechko, S., Luijendijk, E., \& Cardenas, M. B. (2016). The global volume and distribution of modern groundwater. Nature Geosci, 9(2), 161-167. https://doi.org/10.1038/ngeo2590

This article is protected by copyright. All rights reserved. 
Grabs, T., Seibert, J., Bishop, K., \& Laudon, H. (2009). Modeling spatial patterns of saturated areas: A comparison of the topographic wetness index and a dynamic distributed model. Journal of Hydrology, 373(1-2), 15-23. https://doi.org/10.1016/j.jhydrol.2009.03.031

Green, C. T., Jurgens, B. C., Zhang, Y., Starn, J. J., Singleton, M. J., \& Esser, B. K. (2016). Regional oxygen reduction and denitrification rates in groundwater from multi-model residence time distributions, San Joaquin Valley, USA. Journal of Hydrology, 543, 155-166. https://doi.org/10.1016/j.jhydrol.2016.05.018

Güntner, A., Seibert, J., \& Uhlenbrook, S. (2004). Modeling spatial patterns of saturated areas: An evaluation of different terrain indices: SPATIAL PATTERNS OF SATURATED AREAS. Water Resources Research, 40(5). https://doi.org/10.1029/2003WR002864

Haitjema, H. M. (1995). Analytic element modeling of groundwater flow. Elsevier. https://doi.org/10.1016/B978-0-12-316550-3.X5000-4

Haitjema, H. M., \& Mitchell- Bruker, S. (2005). Are Water Tables a Subdued Replica of the Topography? Groundwater, 43(6), 781-786. https://doi.org/10.1111/j.17456584.2005.00090.x

Harbaugh, A. W. (2005). MODFLOW-2005 : the U.S. Geological Survey modular groundwater model--the ground-water flow process (Report No. 6-A16). https://doi.org/10.3133/tm6A16

Harman, C. J. (2015). Time-variable transit time distributions and transport: Theory and application to storage-dependent transport of chloride in a watershed. Water Resources Research, 51(1), 1-30. https://doi.org/10.1002/2014wr015707

Hrachowitz, M., Soulsby, C., Tetzlaff, D., \& Speed, M. (2010). Catchment transit times and landscape controls-does scale matter?: SCIENTIFIC BRIEFING. Hydrological Processes, 24(1), 117-125. https://doi.org/10.1002/hyp.7510

This article is protected by copyright. All rights reserved. 
Hrachowitz, M., Savenije, H. H. G., Bloschl, G., McDonnell, J. J., Sivapalan, M., Pomeroy, J. W., et al. (2013). A decade of Predictions in Ungauged Basins (PUB)a review. Hydrological Sciences Journal-Journal Des Sciences Hydrologiques, 58(6), 11981255. https://doi.org/10.1080/02626667.2013.803183

IAEA. (2006). Use of Chlorofluorocarbons in Hydrology. Vienna: INTERNATIONAL $\begin{array}{llll}\text { ATOMIC } & \text { ENERGY } & \text { Retrieved }\end{array}$ https://www.iaea.org/publications/7187/use-of-chlorofluorocarbons-in-hydrology

IGN. (2018). Institut National de l'Information Géographique et Forestière - RGE ALTI® Version 2.0 - Les modèles numériques 3D - Descriptif de contenu., 38p.

Infascelli, R., Faugno, S., Pindozzi, S., Boccia, L., \& Merot, P. (2013). Testing Different Topographic Indexes to Predict Wetlands Distribution. Procedia Environmental Sciences, 19, 733-746. https://doi.org/10.1016/j.proenv.2013.06.082

Jasechko, S., Perrone, D., Befus, K. M., Bayani Cardenas, M., Ferguson, G., Gleeson, T., et al. (2017). Global aquifers dominated by fossil groundwaters but wells vulnerable to modern contamination. Nature Geoscience, 10(6), 425-429. https://doi.org/10.1038/ngeo2943

Ju, Y., Massoudieh, A., Green, C. T., Lee, K.-K., \& Kaown, D. (2021). Complexity of groundwater age mixing near a seawater intrusion zone based on multiple tracers and Bayesian inference. Science of The Total Environment, 753, 141994. https://doi.org/10.1016/j.scitotenv.2020.141994

Kaandorp, V. P., de Louw, P. G. B., van der Velde, Y., \& Broers, H. P. (2018). Transient Groundwater Travel Time Distributions and Age-Ranked Storage-Discharge Relationships of Three Lowland Catchments. Water Resources Research, 54(7), 45194536. https://doi.org/10.1029/2017wr022461

This article is protected by copyright. All rights reserved. 
Kinzelbach, W. (1988). The Random Walk Method in Pollutant Transport Simulation. In E. Custodio, A. Gurgui, \& J. P. L. Ferreira (Eds.), Groundwater Flow and Quality Modelling (pp. 227-245). Dordrecht: Springer Netherlands. https://doi.org/10.1007/978-94-009-2889-3_15

Kirchner, J. W., Feng, X., \& Neal, C. (2000). Fractal stream chemistry and its implications for contaminant transport in catchments. Nature, 403(6769), 524-527. https://doi.org/10.1038/35000537

Kirkby, M. J. (1978). Hillslope Hydrology. John Wiley, Hoboken, N. J.

Koh, E.-H., Lee, E., Kaown, D., Green, C. T., Koh, D.-C., Lee, K.-K., \& Lee, S. H. (2018). Comparison of groundwater age models for assessing nitrate loading, transport pathways, and management options in a complex aquifer system. Hydrological Processes, 32(7), 923-938. https://doi.org/10.1002/hyp.11465

Kolbe, T., Marçais, J., Thomas, Z., Abbott, B. W., de Dreuzy, J.-R., Rousseau-Gueutin, P., et al. (2016). Coupling 3D groundwater modeling with CFC-based age dating to classify local groundwater circulation in an unconfined crystalline aquifer. Journal of Hydrology, 543, 31-46. https://doi.org/10.1016/j.jhydrol.2016.05.020

Lane, D., McCarter, C. P. R., Richardson, M., McConnell, C., Field, T., Yao, H., et al. (2020). Wetlands and low- gradient topography are associated with longer hydrologic transit times in Precambrian Shield headwater catchments. Hydrological Processes, 34(3), 598-614. https://doi.org/10.1002/hyp.13609

Leray, S., de Dreuzy, J.-R., Bour, O., Labasque, Th., \& Aquilina, L. (2012). Contribution of age data to the characterization of complex aquifers. Journal of Hydrology, 464-465, 54-68. https://doi.org/10.1016/j.jhydrol.2012.06.052

Leray, S., Engdahl, N. B., Massoudieh, A., Bresciani, E., \& McCallum, J. (2016). Residence time distributions for hydrologic systems: Mechanistic foundations and steady-state 
analytical solutions. Journal of Hydrology, 543, 67-87. https://doi.org/10.1016/j.jhydrol.2016.01.068

Leray, S., De Dreuzy, J.-R., Bour, O., \& Bresciani, E. (2018). Structural controls of groundwater resources in fractured rock aquifers. In XV Congreso Geológico Chileno (p. 643). Conception, Chile. Retrieved from https://hal-insu.archives-ouvertes.fr/insu02048167

Leray, S., Gauvain, A., \& de Dreuzy, J.-R. (2019). Residence time distributions in non-uniform aquifer recharge and thickness conditions - An analytical approach based on the assumption of Dupuit-Forchheimer. Journal of Hydrology, 574, 110-128. https://doi.org/10.1016/j.jhydrol.2019.04.032

Luther, K. H., \& Haitjema, H. M. (1998). Numerical experiments on the residence time distributions of heterogeneous groundwatersheds. Journal of Hydrology, 207(1-2), 117. https://doi.org/10.1016/S0022-1694(98)00112-7

Lyon, S. W., \& Troch, P. A. (2007). Hillslope subsurface flow similarity: Real-world tests of the hillslope Peclet number. Water Resour. Res., 43(7), 9. https://doi.org/10.1029/2006wr005323

Małoszewski, P., \& Zuber, A. (1982). Determining the turnover time of groundwater systems with the aid of environmental tracers. Journal of Hydrology, 57(3-4), 207-231. https://doi.org/10.1016/0022-1694(82)90147-0

Marçais, J., de Dreuzy, J.-R., \& Erhel, J. (2017). Dynamic coupling of subsurface and seepage flows solved within a regularized partition formulation. Advances in Water Resources, 109, 94-105. https://doi.org/10.1016/j.advwatres.2017.09.008

Massoudieh, A., Sharifi, S., \& Solomon, D. K. (2012). Bayesian evaluation of groundwater age distribution using radioactive tracers and anthropogenic chemicals: UNCERTAINTIES

This article is protected by copyright. All rights reserved. 
IN GROUNDWATER DATING. Water Resources Research, 48(9). https://doi.org/10.1029/2012WR011815

Massoudieh, A., Leray, S., \& de Dreuzy, J.-R. (2014). Assessment of the value of groundwater age time-series for characterizing complex steady-state flow systems using a Bayesian $\begin{array}{llll}\text { approach. } & \text { Applied } & \text { Geochemistry, } & \text { 240-251. }\end{array}$ https://doi.org/10.1016/j.apgeochem.2013.10.006

Matonse, A. H., \& Kroll, C. (2009). Simulating low streamflows with hillslope storage models: SIMULATING LOW STREAMFLOWS. Water Resources Research, 45(1). https://doi.org/10.1029/2007WR006529

McCallum, J. L., Engdahl, N. B., Ginn, T. R., \& Cook, Peter. G. (2014). Nonparametric estimation of groundwater residence time distributions: What can environmental tracer data tell us about groundwater residence time? Water Resources Research, 50(3), 20222038. https://doi.org/10.1002/2013WR014974

McCallum, J. L., Cook, P. G., \& Simmons, C. T. (2015). Limitations of the Use of Environmental Tracers to Infer Groundwater Age. Groundwater, 53(S1), 56-70. https://doi.org/10.1111/gwat.12237

McGuire, K. J., \& McDonnell, J. J. (2006). A review and evaluation of catchment transit time modeling. Journal of Hydrology, 330(3-4), 543-563. https://doi.org/10.1016/j.jhydrol.2006.04.020

McGuire, K. J., McDonnell, J. J., Weiler, M., Kendall, C., McGlynn, B. L., Welker, J. M., \& Seibert, J. (2005). The role of topography on catchment-scale water residence time. Water Resources Research, 41(5). https://doi.org/10.1029/2004wr003657

Merot, Ph., Squividant, H., Aurousseau, P., Hefting, M., Burt, T., Maitre, V., et al. (2003). Testing a climato-topographic index for predicting wetlands distribution along an 
European climate gradient. Ecological Modelling, 163(1-2), 51-71. https://doi.org/10.1016/S0304-3800(02)00387-3

Mougin, B., Allier, D., Blanchin, R., Carn, A., Courtois, N., Gateau, C., \& Putot, E. (2008). Étude réalisée dans le cadre des projets de Service public du BRGM 2007 EAU I23, 131.

Mukherjee, S., Mukherjee, S., Garg, R. D., Bhardwaj, A., \& Raju, P. L. N. (2013). Evaluation of topographic index in relation to terrain roughness and DEM grid spacing. Journal of Earth System Science, 122(3), 869-886. https://doi.org/10.1007/s12040-013-0292-0

Neuman, S. P., \& Witherspoon, P. A. (1970). Finite Element Method of Analyzing Steady Seepage with a Free Surface. Water Resources Research, 6(3), 889-897. https://doi.org/10.1029/WR006i003p00889

Newman, B. D., Osenbrück, K., Aeschbach-Hertig, W., Kip Solomon, D., Cook, P., Różański, K., \& Kipfer, R. (2010). Dating of 'young' groundwaters using environmental tracers: advantages, applications, and research needs. Isotopes in Environmental and Health Studies, 46(3), 259-278. https://doi.org/10.1080/10256016.2010.514339

Niswonger, R. G., Panday, S., \& Ibaraki, M. (2011). MODFLOW-NWT, A Newton formulation for MODFLOW-2005, p. 44.

Ogden, F. L., \& Watts, B. A. (2000). Saturated area formation on nonconvergent hillslope topography with shallow soils: A numerical investigation. Water Resources Research, 36(7), 1795-1804. https://doi.org/10.1029/2000WR900091

Piessens, R., de Doncker-Kapenga, E., Überhuber, C. W., \& Kahaner, D. K. (1983). QUADPACK - A Subroutine Package for Automatic Integration (Vol. 1). Berlin, Heidelberg: Springer Berlin Heidelberg. https://doi.org/10.1007/978-3-642-61786-7

Pinay, G., Peiffer, S., De Dreuzy, J.-R., Krause, S., Hannah, D. M., Fleckenstein, J. H., et al. (2015). Upscaling Nitrogen Removal Capacity from Local Hotspots to Low Stream 
Orders' Drainage Basins. Ecosystems, 18(6), 1101-1120. https://doi.org/10.1007/s10021-015-9878-5

Pollock, D. W. (2016). User guide for MODPATH Version 7-A particle-tracking model for MODFLOW (Report No. 2016-1086) (p. 41). Reston, VA. https://doi.org/10.3133/ofr20161086

Reichstein, M., Camps-Valls, G., Stevens, B., Jung, M., Denzler, J., Carvalhais, N., \& Prabhat, null. (2019). Deep learning and process understanding for data-driven Earth system science. Nature, 566(7743), 195-204. https://doi.org/10.1038/s41586-019-0912-1

Remondi, F., Kirchner, J. W., Burlando, P., \& Fatichi, S. (2018). Water Flux Tracking With a Distributed Hydrological Model to Quantify Controls on the Spatio-temporal Variability of Transit Time Distributions. Water Resources Research, 54(4), 30813099. https://doi.org/10.1002/2017wr021689

Remondi, F., Botter, M., Burlando, P., \& Fatichi, S. (2019). Variability of transit time distributions with climate and topography: A modelling approach. Journal of Hydrology, 569, 37-50. https://doi.org/10.1016/j.jhydrol.2018.11.011

Rempe, D. M., \& Dietrich, W. E. (2014). A bottom-up control on fresh-bedrock topography under landscapes. Proceedings of the National Academy of Sciences, 111(18), 65766581. https://doi.org/10.1073/pnas.1404763111

Rodríguez-Iturbe, I., \& Valdés, J. B. (1979). The geomorphologic structure of hydrologic response. Water Resources Research, 15(6), 1409-1420. https://doi.org/10.1029/WR015i006p01409

Rosenberry, D. O., \& Winter, T. C. (1997). Dynamics of water-table fluctuations in an upland between two prairie-pothole wetlands in North Dakota. Journal of Hydrology, 191(1), 266-289. https://doi.org/10.1016/S0022-1694(96)03050-8

This article is protected by copyright. All rights reserved. 
Sabzevari, T., Talebi, A., Ardakanian, R., \& Shamsai, A. (2010). A steady-state saturation model to determine the subsurface travel time (STT) in complex hillslopes. Hydrology and Earth System Sciences, 14(6), 891-900. https://doi.org/10.5194/hess-14-891-2010

Schwanghart, W., \& Scherler, D. (2014). Short Communication: TopoToolbox 2 - MATLABbased software for topographic analysis and modeling in Earth surface sciences. Earth Surface Dynamics, 2(1), 1-7. https://doi.org/10.5194/esurf-2-1-2014

Seeger, S., \& Weiler, M. (2014). Reevaluation of transit time distributions, mean transit times and their relation to catchment topography. Hydrology and Earth System Sciences, 18(12), 4751-4771. https://doi.org/10.5194/hess-18-4751-2014

Shangguan, W., Hengl, T., Jesus, J. M. de, Yuan, H., \& Dai, Y. (2017). Mapping the global depth to bedrock for land surface modeling. Journal of Advances in Modeling Earth Systems, 9(1), 65-88. https://doi.org/10.1002/2016MS000686

Sprenger, M., Stumpp, C., Weiler, M., Aeschbach, W., Allen, S. T., Benettin, P., et al. (2019). The Demographics of Water: A Review of Water Ages in the Critical Zone. Reviews of Geophysics, 57(3), 800-834. https://doi.org/10.1029/2018rg000633

Starn, J. J., \& Belitz, K. (2018). Regionalization of Groundwater Residence Time Using Metamodeling. Water Resources Research, 54(9), 6357-6373. https://doi.org/10.1029/2017WR021531

Stotler, R., Harvey, F. E., \& Gosselin, D. C. (2009). A Black Hills-Madison Aquifer Origin for Dakota Aquifer Groundwater in Northeastern Nebraska. Ground Water, 48(3), 448464. https://doi.org/10.1111/j.1745-6584.2009.00636.x

Tetzlaff, D., Seibert, J., McGuire, K. J., Laudon, H., Burn, D. A., Dunn, S. M., \& Soulsby, C. (2009). How does landscape structure influence catchment transit time across different geomorphic provinces? Hydrological Processes, 23(6), 945-953. https://doi.org/10.1002/hyp.7240

This article is protected by copyright. All rights reserved. 
Troch, P. A., van Loon, E., \& Hilberts, A. (2002). Analytical solutions to a hillslope-storage kinematic wave equation for subsurface flow. Advances in Water Resources, 25(6), 637-649. https://doi.org/10.1016/S0309-1708(02)00017-9

Troch, P. A., Paniconi, C., \& van Loon, E. (2003). Hillslope-storage Boussinesq model for subsurface flow and variable source areas along complex hillslopes: 1. Formulation and characteristic response: HILLSLOPE-STORAGE BOUSSINESQ MODEL, 1. Water Resources Research, 39(11). https://doi.org/10.1029/2002WR001728

Troldborg, L., Refsgaard, J. C., Jensen, K. H., \& Engesgaard, P. (2007). The importance of alternative conceptual models for simulation of concentrations in a multi-aquifer system. Hydrogeology Journal, 15(5), 843-860. https://doi.org/10.1007/s10040-0070192-y

Troldborg, L., Jensen, K. H., Engesgaard, P., Refsgaard, J. C., \& Hinsby, K. (2008). Using Environmental Tracers in Modeling Flow in a Complex Shallow Aquifer System. Journal of Hydrologic Engineering, 13(11), 1037-1048. https://doi.org/10.1061/(ASCE)1084-0699(2008)13:11(1037)

Underwood, S. C., McCallum, J. L., Cook, P. G., Simmons, C. T., Dogramaci, S., Purtschert, R., et al. (2018). Physical and Chemical Controls on the Simultaneous Occurrence of Young and Old Groundwater Inferred From Multiple Age Tracers. Water Resources Research, 54(11), 9514-9532. https://doi.org/10.1029/2018wr022800

Virtanen, P., Oliphant, T. E., Haberland, M., Reddy, T., Cournapeau, D., Burovski, E., et al. (2020). SciPy 1.0: fundamental algorithms for scientific computing in Python. Nature Methods, 17(3), 261-272. https://doi.org/10.1038/s41592-019-0686-2

Visser, A., Broers, H. P., Purtschert, R., Sültenfuß, J., \& de Jonge, M. (2013). Groundwater age distributions at a public drinking water supply well field derived from multiple age tracers $\left({ }^{85} \mathrm{Kr},{ }^{3} \mathrm{H} /{ }^{3} \mathrm{He}\right.$, and $\left.{ }^{39} \mathrm{Ar}\right)$ : Groundwater Age Distributions at a Drinking Water 
Well Field. Water Resources Research, 49(11), 7778-7796. https://doi.org/10.1002/2013WR014012

Wachniew, P., Zurek, A. J., Stumpp, C., Gemitzi, A., Gargini, A., Filippini, M., et al. (2016). Toward operational methods for the assessment of intrinsic groundwater vulnerability: A review. Critical Reviews in Environmental Science and Technology, 46(9), 827-884. https://doi.org/10.1080/10643389.2016.1160816

Yang, J., Heidbuchel, I., Musolff, A., Reinstorf, F., \& Fleckenstein, J. H. (2018). Exploring the Dynamics of Transit Times and Subsurface Mixing in a Small Agricultural Catchment. Water Resources Research, 54(3), 2317-2335. https://doi.org/10.1002/2017wr021896

Zuber, A., Małoszewski, P., Stichler, W., \& Herrmann, A. (1986). Tracer relations in variable flow. 5th International Symposium on Underground Water Tracing. Institute of Geology and Mineral Exploration (IGME), Athens: 45-57.

Zuber, A., Różański, K., Kania, J., \& Purtschert, R. (2011). On some methodological problems in the use of environmental tracers to estimate hydrogeologic parameters and to calibrate flow and transport models. Hydrogeology Journal, 19(1), 53-69. https://doi.org/10.1007/s10040-010-0655-4

This article is protected by copyright. All rights reserved. 


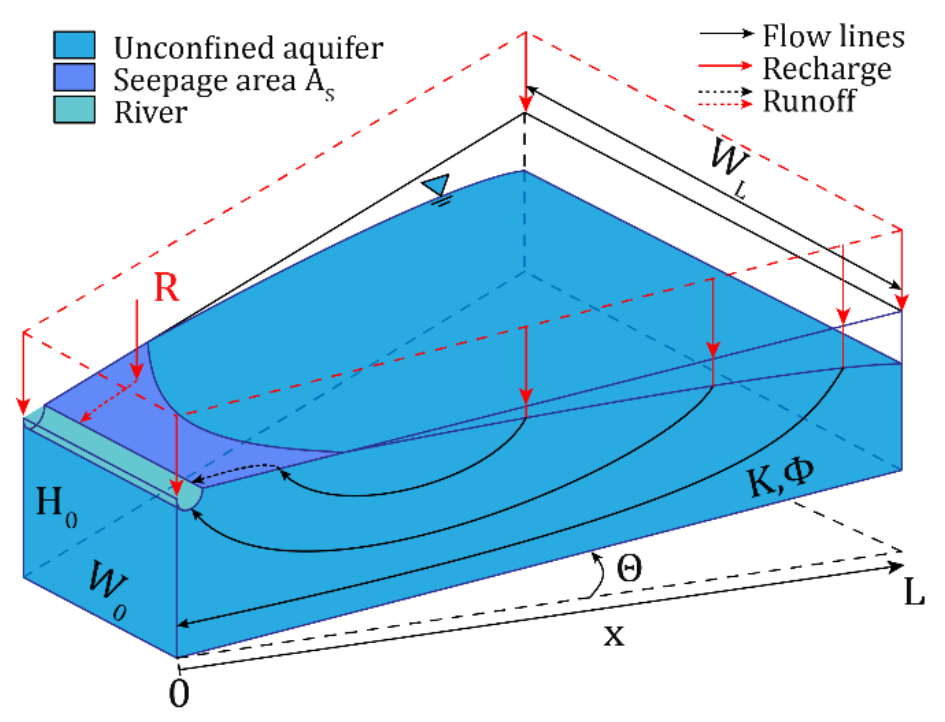

Figure 1 - Synthetic hillslope models with their parameters.

This article is protected by copyright. All rights reserved. 

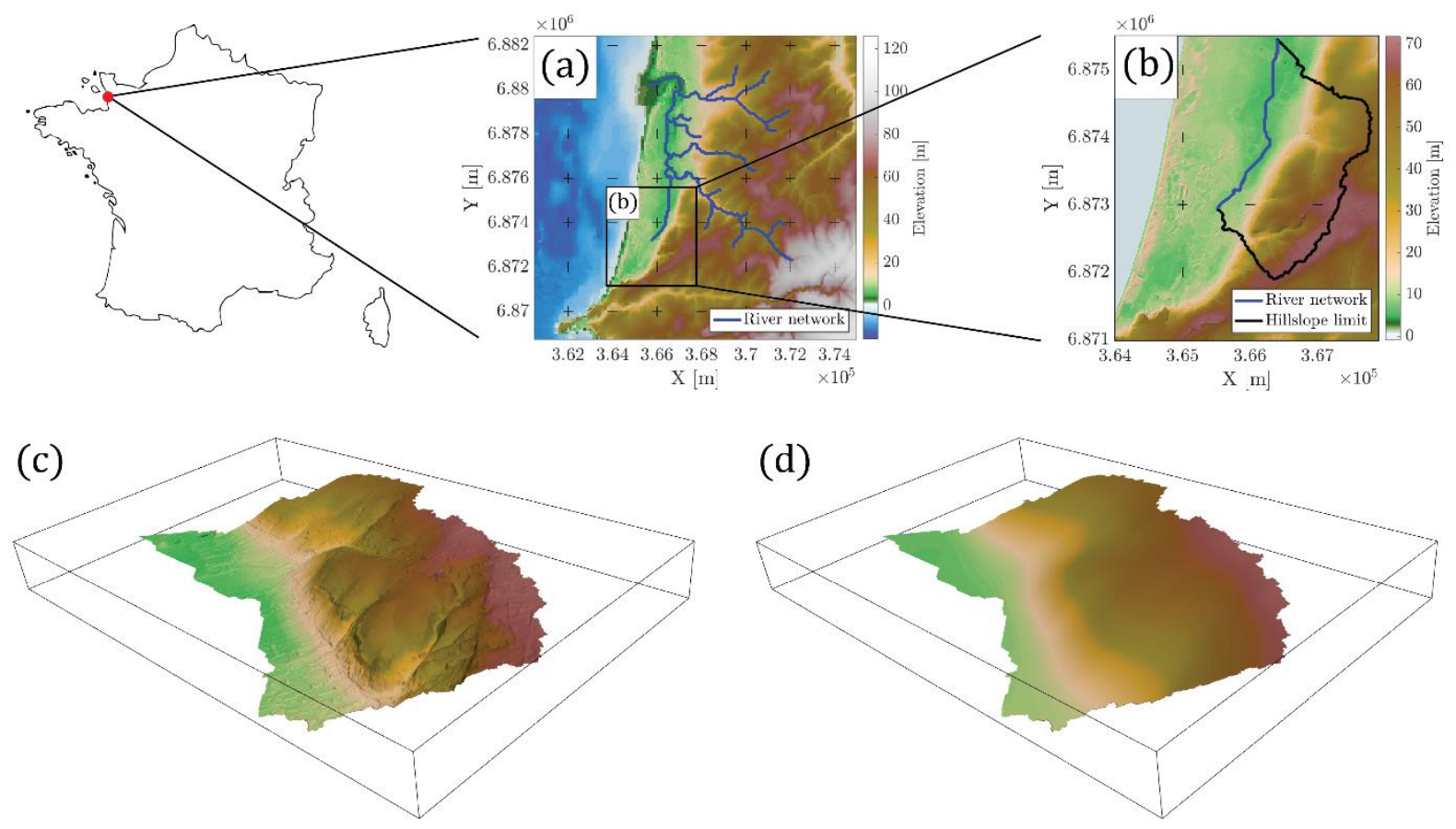

Figure 2 - Hillslope location (b) in the Normandy catchment (a). 3D visualizations for a real topography at a resolution of $5 \mathrm{~m}(\mathrm{c})$ and the smoothed topography obtained with a smoothing scale of $500 \mathrm{~m}(\mathrm{~d})$.

This article is protected by copyright. All rights reserved. 

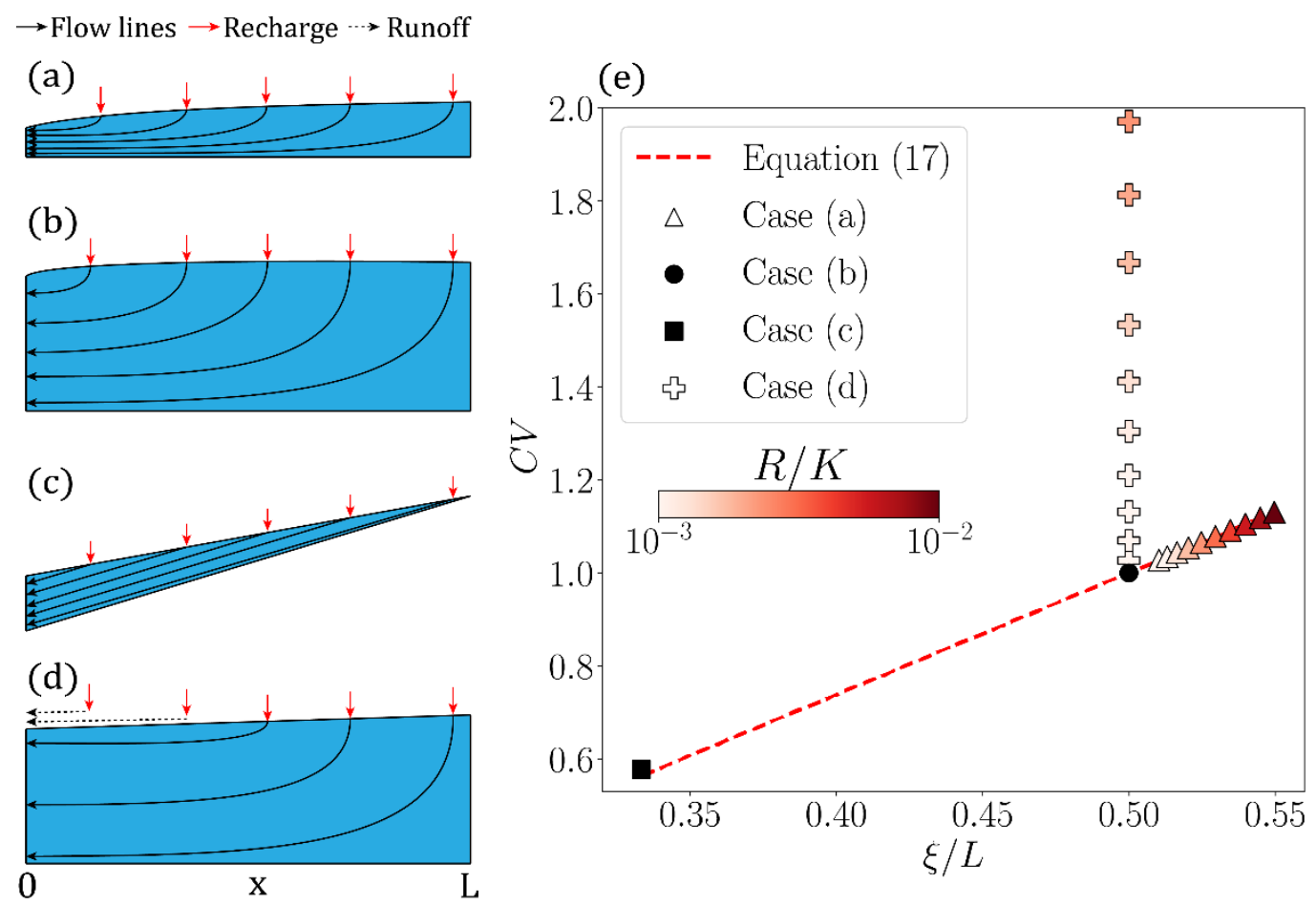

Figure 3 - Sketches of systems for which TTDs are derived analytically: (a) thin flat aquifers, (b) thick flat aquifers, (c) steep aquifers and (d) aquifers with a seepage area. (e) Corresponding coefficient of variations $C V$ as a function of the barycenter of the aquifer volume $\xi$ normalized by the hillslope length $L$ derived for straight aquifers $\left(C_{W}=1\right)$.

This article is protected by copyright. All rights reserved. 

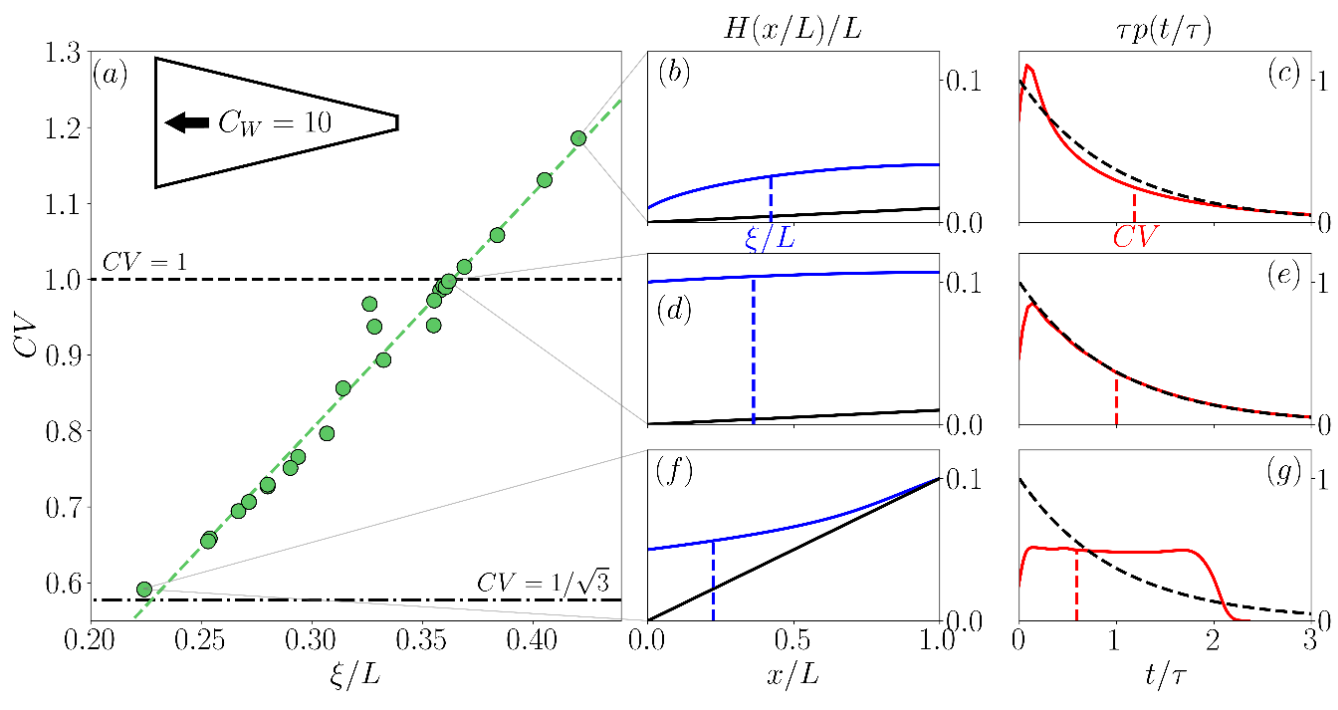

Figure 4 - (a) $C V$ as a function of $\xi / L$ for divergent synthetic hillslopes $\left(C_{w}=10\right)$. (b), (d) and (f): cross-sections of the hillslope with the hydraulic head in blue and the bedrock boundary in black. (c), (e) and (g): TTDs in red solid lines compared to the exponential model (black dashed line) for 3 models with high $C V$ (top line), low $C V$ (bottom line) and with a $C V$ value close to 1. 


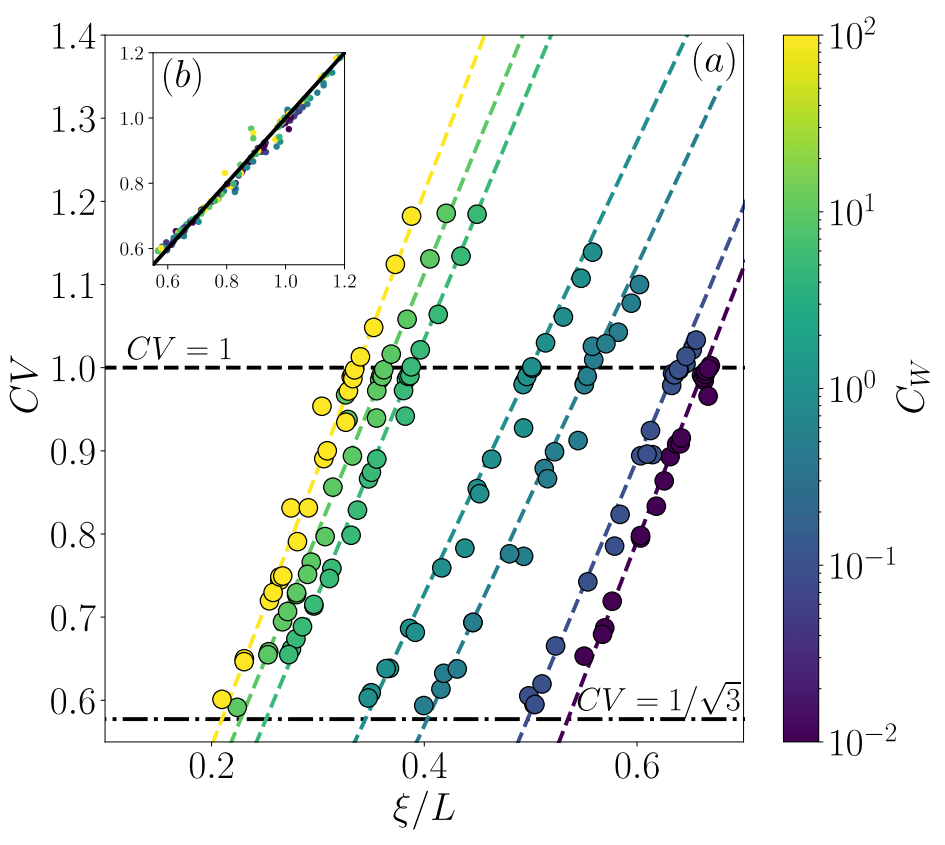

Figure 5 - (a) $C V$ versus $\xi / L$ for the synthetic hillslope models without seepage. Colors refer to different values of $C_{W}$ (scale given on the right). Diagonal dashed lines come from equations (28) and (29) with numerical estimates of $\xi_{U}$. (b) The insert on the top shows the agreement between analytical and numerical results ( $x$ - and $y$-axes).

This article is protected by copyright. All rights reserved. 

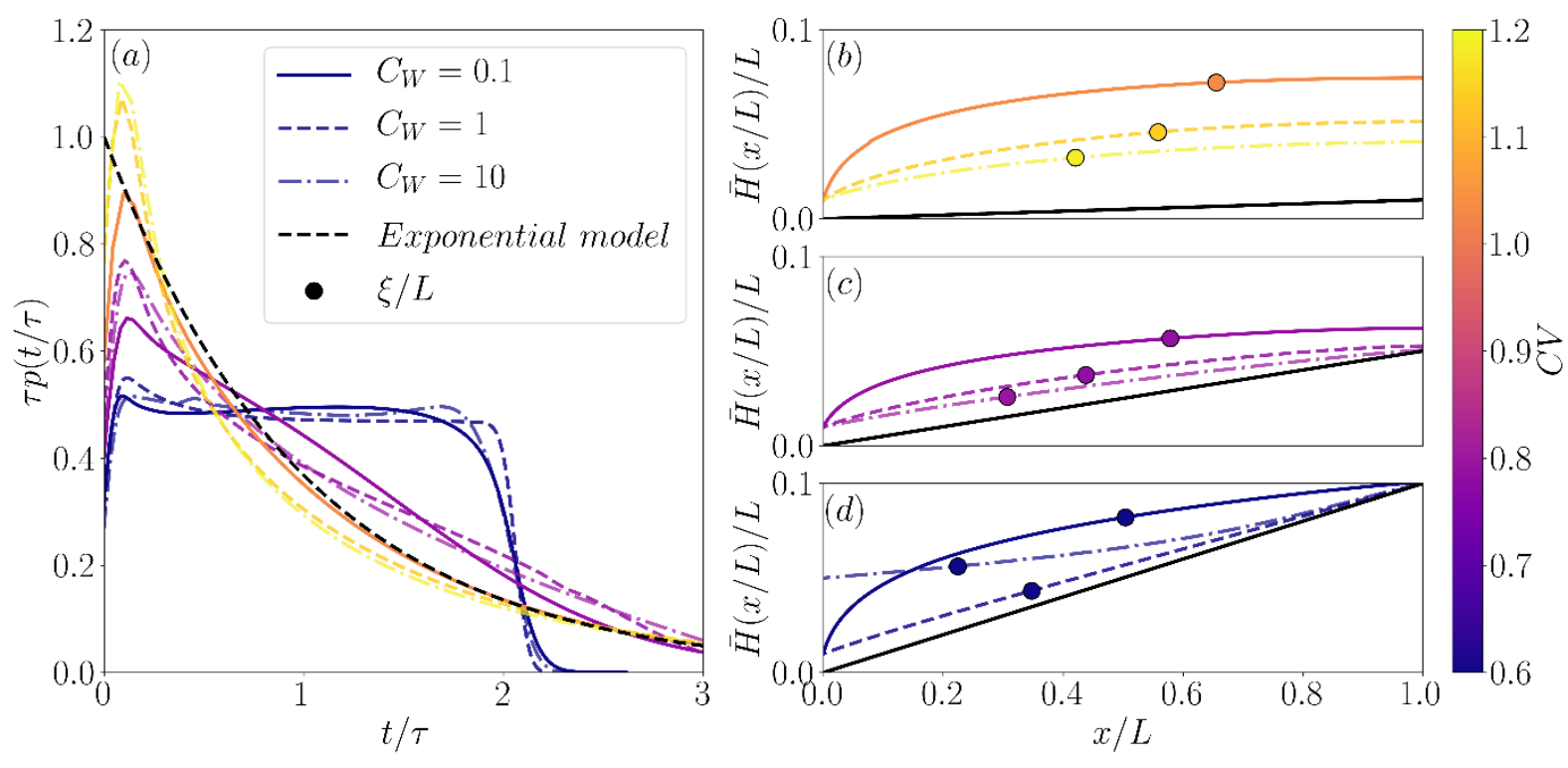

Figure 6. (a) TTDs scaled by the mean transit time $\tau$ for three values of $C_{W}$ (solid line for $C_{W}=$ 0. 1, dashed line for $C_{W}=1$ and dotted dashed line for $C_{W}=10$ ) as compared to the exponential model (black dash line). The colorbar represents the coefficient of variation $C V$ of the TTD. The three figures on the right show the normalized mean hydraulic head $\bar{H}(x / L) / L$ and the location of the normalized barycenter of the aquifer volume $\xi / L$ for three different slopes: $1 \%$ for $(b), 5 \%$ for (c) and $10 \%$ for (d). The black line represents the limit of the bedrock.

This article is protected by copyright. All rights reserved. 

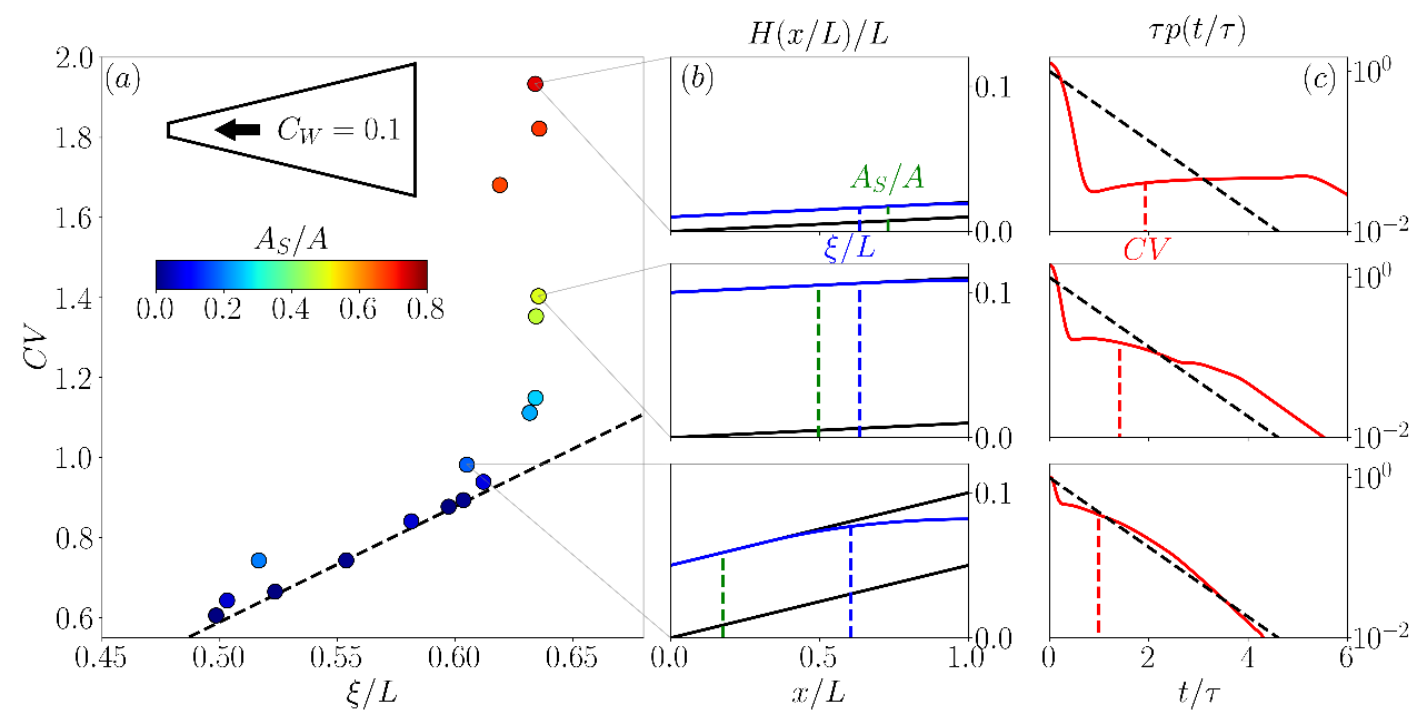

Figure 7. (a) $C V$ against $\xi / L$ for convergent hillslopes with an upper topographic limit generating seepage $\left(C_{W}=0.1\right)$. (b) Cross-section with hydraulic head profiles in blue, bedrock limit and topographic boundary in black where the normalized positions of the volume barycenter $(\xi / L)$ and of the limit of the seepage zone $\left(A_{S}\right)$ are marked by the dashed vertical blue and green lines. (c) TTDs of the underground contribution in red compared to the exponential model in dashed black lines shown for 3 models with maximal and median values of $A_{S} / A$ (top and middle lines) and the closest model to $C V=1$ (bottom line). 

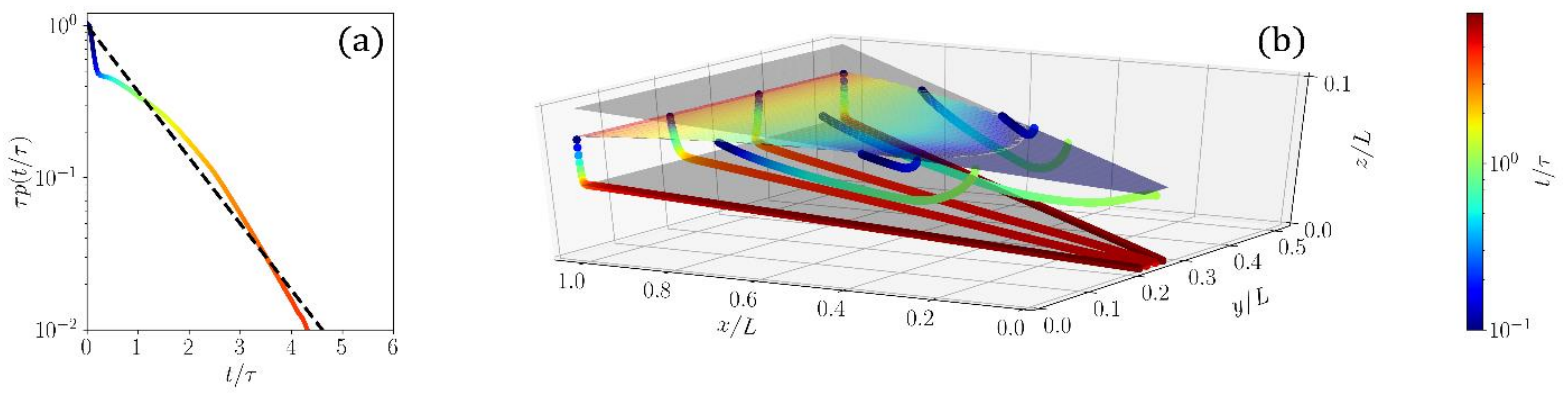

Figure 8. Relation of the TTD (a) to the pathline structure for a convergent hillslope with seepage (b). The color of the pathlines represents the normalized time. The model parameters are $C_{W}=0.1, R / K=0.002, H_{0} / L=0.05, \Theta=0.05$ and $A_{S} / A=0.18$. 


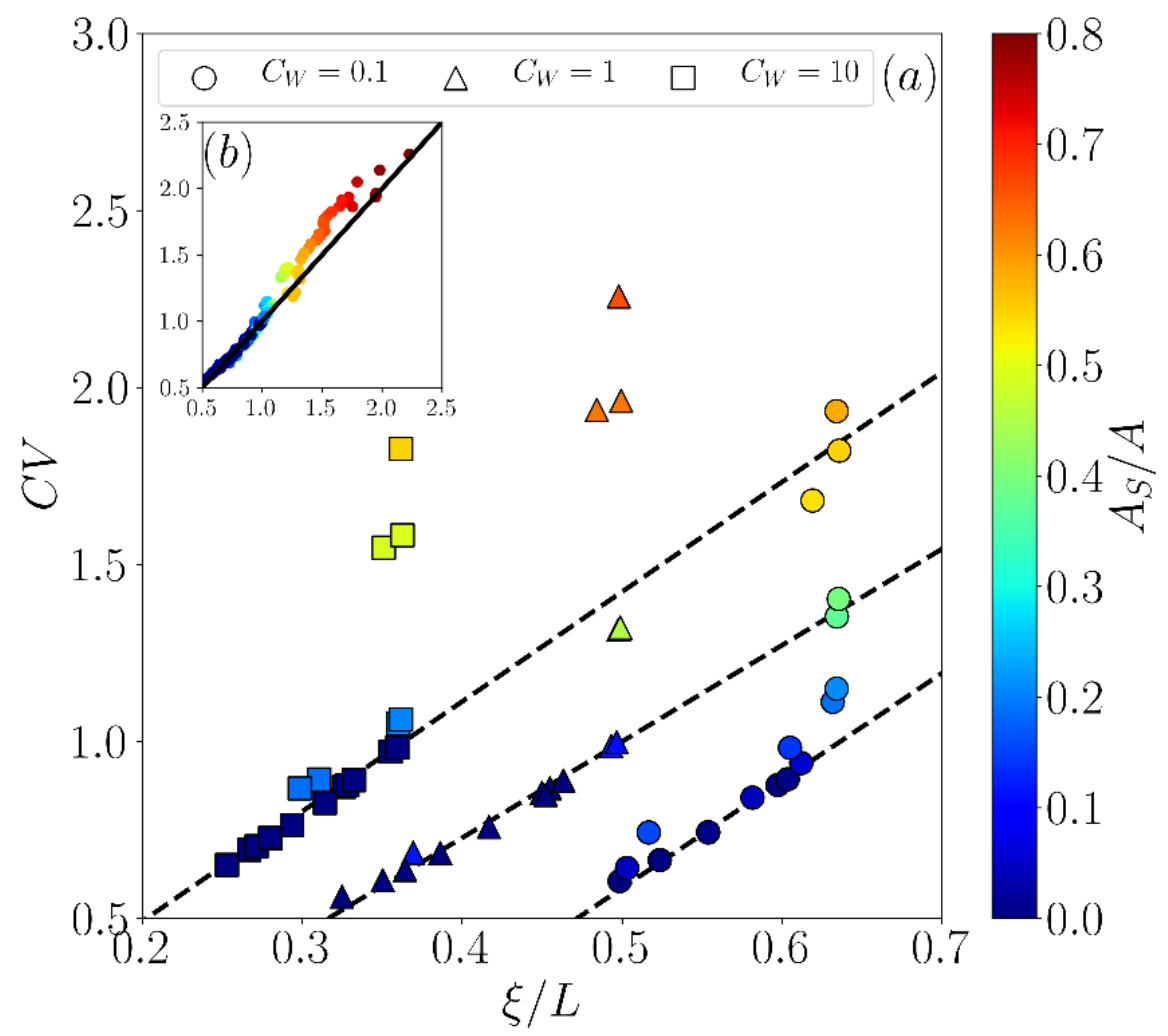

Figure 9. Coefficient of Variation $C V$ against $\xi L$ for convergent, straight and divergent hillslopes for increasingly bigger seepage areas. Insert: comparison of the analytical estimates of $\mathrm{CV}$ given by equation (32) and the numerical values.

This article is protected by copyright. All rights reserved. 
(a)

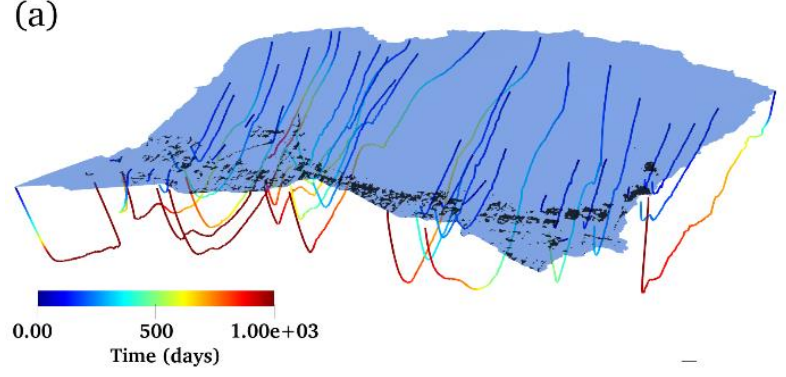

(b)

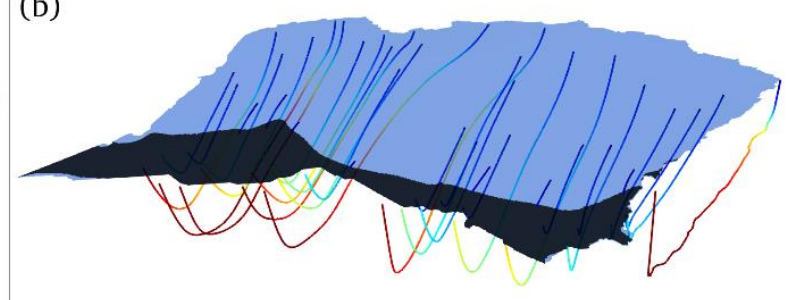

Figure 10. Illustration of some of the flow lines for the real (a) and smoothed (b) natural hillslope cases (see Figure 2). Smoothing scale in (b) is set $500 \mathrm{~m}$. Colors represent the transit time along the flow lines. The blue transparent surface indicates the elevation of the water table. The black surface delineates the seepage areas. Results are shown for $R / K=2.10^{-3}$ and $H_{0}=50 \mathrm{~m}$.

This article is protected by copyright. All rights reserved. 


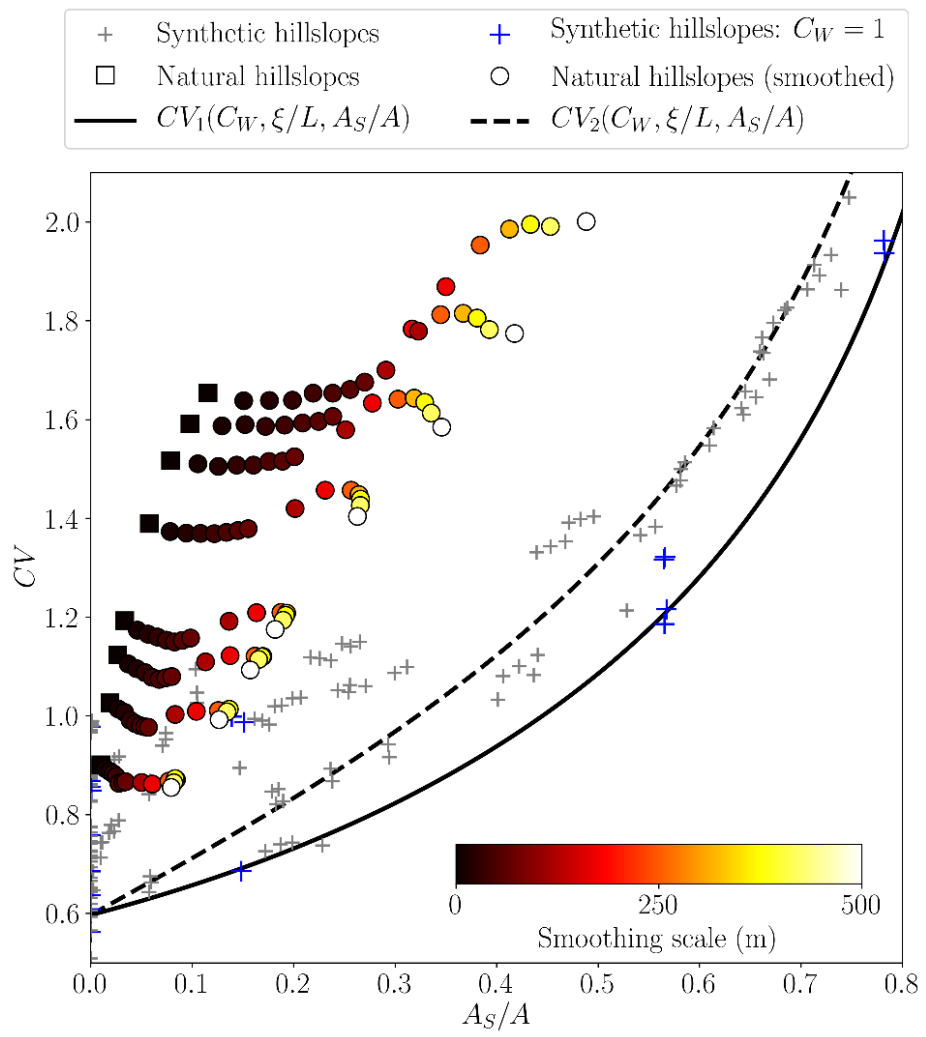

Figure 11. Coefficient of variation $C V$ against the seepage ratio $A_{S} / A$ for the synthetic hillslopes (gray crosses), the straight $\left(C_{W}=1\right)$ synthetic hillslopes (blue crosses), the natural hillslopes (black squares), the smoothed natural hillslopes with evolving smoothing scale (colored disks). Equations (32) and (35) (respectively black dashed and solid lines) are generated using the $C_{W}$ and $\xi / L$ values of the natural hillslope model.

This article is protected by copyright. All rights reserved. 


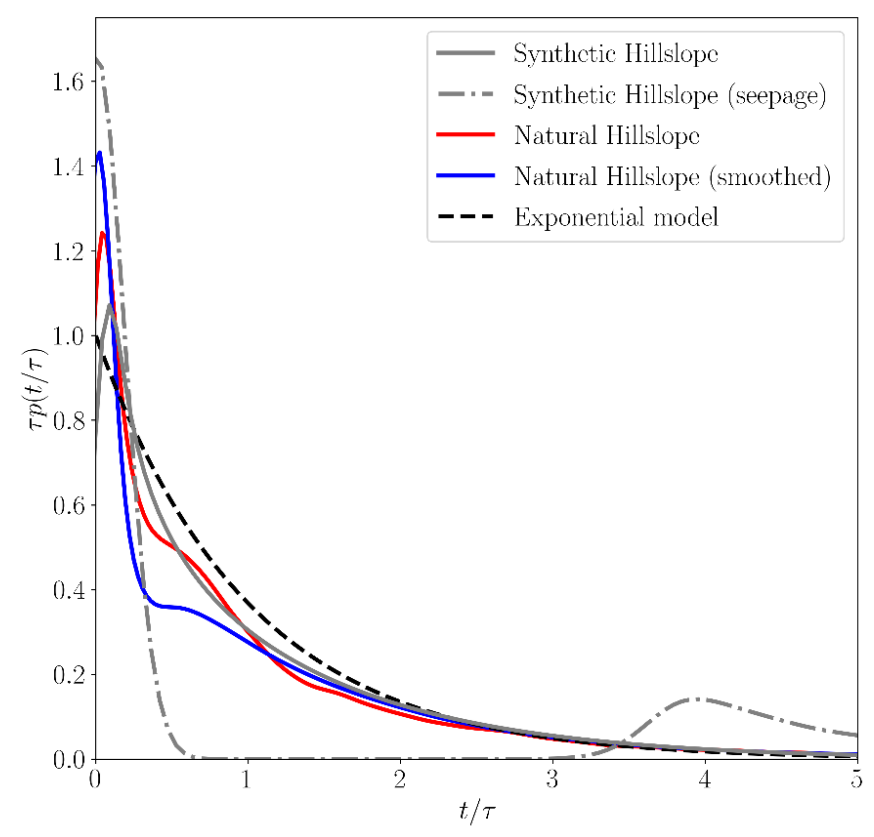

Figure 12. TTDs compared to the exponential model (black dashed line) for the synthetic hillslope $(C V=1.14$; gray line), the synthetic hillslope with seepage $(C V=1.96$; gray dash-line), the natural hillslope ( $C V=1.39$; red line) and the smoothed natural hillslope with the maximal smoothing scale of $500 \mathrm{~m}(\mathrm{CV}=1.46$; blue line $)$. Results are shown for $H_{0}=50 \mathrm{~m}, C_{W}=1$ and $R / K=0.002$.

This article is protected by copyright. All rights reserved. 


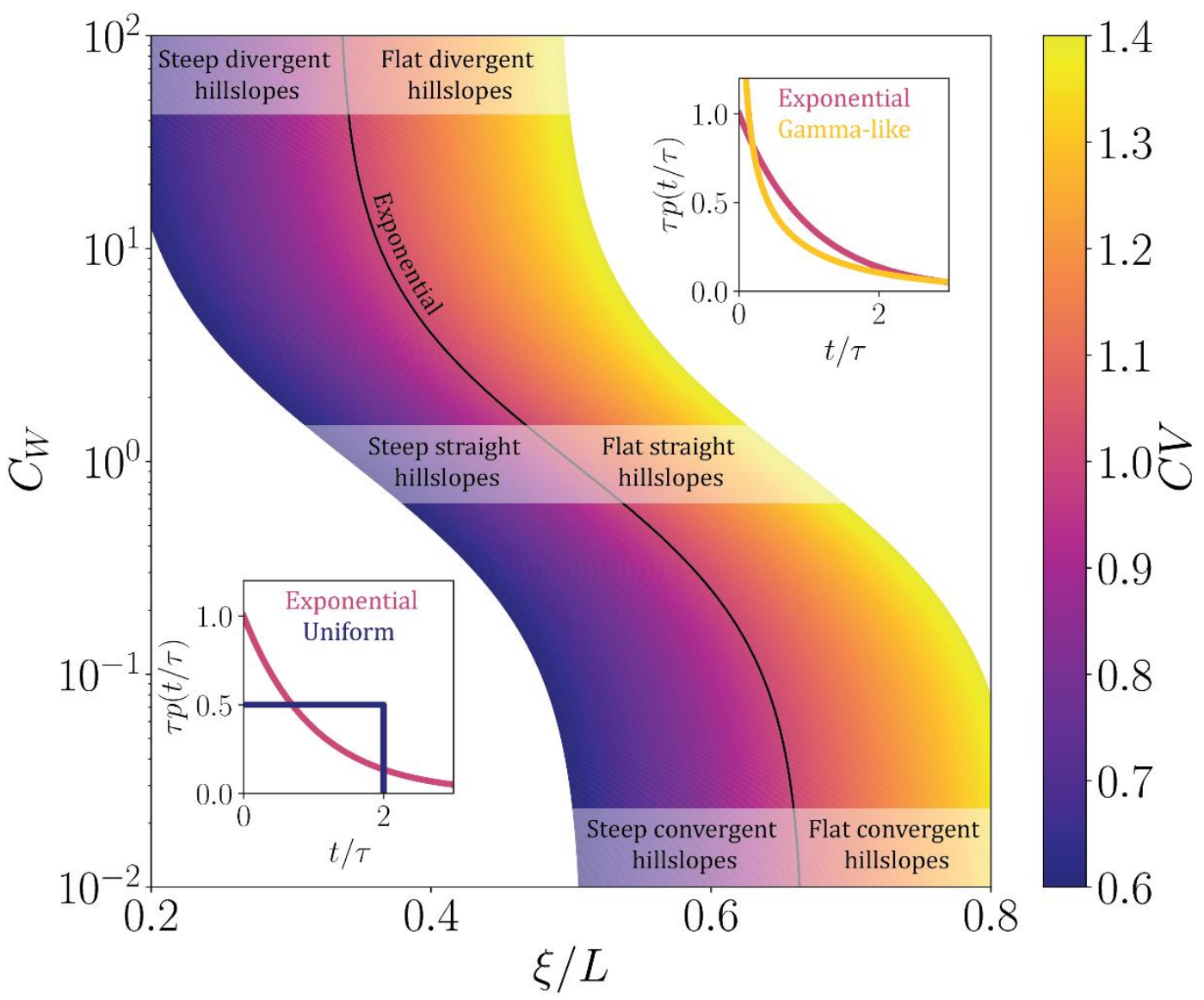

Figure 13. $C V$ as a function of $C_{W}$ and $\xi / L$ according to equation (28). Hillslope cases without seepage have been placed on the graph with TDDs evolving from the uniform model (purple color) to the exponential model (pink color) and gamma like model (orange/yellow colors).

This article is protected by copyright. All rights reserved. 


\begin{tabular}{|c|c|}
\hline PARAMETERS & VALUES \\
\hline $\mathbf{C}_{\mathbf{w}}=\mathbf{W}_{\mathbf{0}} / \mathbf{W}_{\mathbf{L}}$ & $0.01-0.1-0.5-1-5-10-100$ \\
\hline $\boldsymbol{H}_{\mathbf{0}} / \boldsymbol{L}$ & $0.01-0.05-0.1$ \\
\hline $\boldsymbol{\Theta}$ & $0.01-0.05-0.1$ \\
\hline $\boldsymbol{R} / \boldsymbol{K}$ & $0.0005-0.001-0.002$ \\
\hline
\end{tabular}

Table 1. Parameters and values investigated for the synthetic hillslope model.

This article is protected by copyright. All rights reserved. 